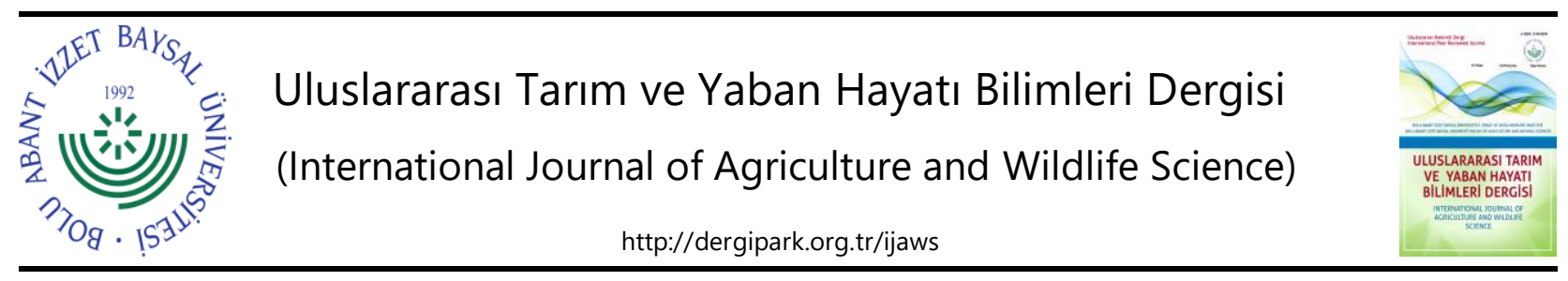

Araştırma Makalesi

\title{
Farklı Cidar Kalınlıklarına Sahip Buğday Silosunda Doldurma ve Boşaltma Koşullarına Bağlı Olarak Gerilme Dağılımının Simülasyonu
}

\author{
Hakan Kibar \\ Bolu Abant İzzet Baysal Üniversitesi, Ziraat Fakültesi, Tohum Bilimi ve Teknolojisi Bölümü, Bolu \\ Geliş tarihi (Received): 18.09.2020Ｋabul tarihi (Accepted): 12.11 .2020
}

Anahtar kelimeler:
Çelik silo, doldurma,
boşaltma, basınç yükleri,
gerilme

*Sorumlu yazar

hakan.kibar@ibu.edu.tr

\begin{abstract}
Özet. Ticari amaçlı planlanan silolarının tasarımı ve geliştirilmesi, yapısal performansının ve yüklerinin güçlü bir şekilde anlaşılmasını gerektirir. Bu çalışmada sınırlı sayıda araştırma, depolanmış ürünlerin silolar üzerindeki etkisini araştırmıştır. Bu nedenle buğday tahııının depolaması için huni tabanlı, ticari amaçlı farklı cidar kalınlığına sahip çelik konstrüksiyonlu Silo 1 ve Silo 2 modelleri tasarlanmıştır. Bu amaçla araştırmada 1306 ton ve 610 ton depolama kapasitesine sahip iki farklı model siloda 3, 4, 5, 7, 8, 9 ve 10 mm cidar kalınlıklarının güvenli bir depolamada kullanılabilirlikleri araştırılmıştır. Öncelikle Eurocode $1^{\prime} \mathrm{e}$ göre model silo cidarları üzerindeki basınç yükleri hesaplanmıştır. Daha sonra buğday silolarının tam ölçekli sonlu eleman modeli (FEM) geliştirilmiş ve silolar ürünün doldurulması ve boşaltılması durumuna göre ANSYS ${ }^{\circledR}$ yazılımı ile simüle edilmiştir. Depolanan buğday ve silo gövdesi etkileşimleri, hem buğdayın hem de çelik silonun karakteristik özellikleri gözönüne alınarak, minimum basitleştirme ile modellenmiştir. Araştırma sonucunda her iki silo modelinde doldurma ve boşaltma koşullarındaki basınç yükleri silonun tepe noktasından boşaltma ağzına doğru artış göstermiştir. Doldurma ve boşaltma koşuluna göre düşük cidar kalınlıklarının daha fazla basınç yüküne maruz kaldıkları belirlenmiştir. Maksimum basınç yükleri Silo 1 'de huni bölgesinde ortaya çıkarken Silo 2'de geçiş bölgesinde ortaya çıkmıştır. ANSYS simülasyonu sonucunda her iki silo modeli için maksimum deformasyonlar geçiş bölgesinde ve bu bölgenin hemen altında tespit edilmiştir. Modal analiz sonuçlarına göre silo cidar kalınlığının artması ile frekans değerlerininde arttığı gözlemlenmiştir. Çalışma sonucunda elde edilen veriler ışığında güvenli ve emniyetli depolamanın Silo 1 ve $8 \mathrm{~mm}$ cidar kalınlığında olduğu söylenebilir.
\end{abstract}

\section{Simulation of Stress Distribution Depending on Filling and Discharge Conditions in Wheat Silo with Different Wall Thickness}

\section{Keywords:}

Steel silo, filling, discharge, pressure loads, stress

\begin{abstract}
The design and development of commercially planned silos requires a strong understanding of their structural performance and loads. A limited number of studies have investigated the effect of stored products on silos. For this reason, Silo 1 and Silo 2 models with hopper base and steel construction with different wall thickness for commercial purposes were designed for storage wheat grain. For this purpose, the usability of 3, 4, 5, 7, 8, 9 and $10 \mathrm{~mm}$ wall thicknesses for safe storage was investigated in two different models of silos with 1306 tons and 610 tons of storage capacity. First of all, pressure loads on the model silo walls are calculated according to Eurocode 1. Then, the full-scale finite element model (FEM) of wheat silos was developed and the silos were simulated with ANSYS ${ }^{\circledR}$ software according to the filling and discharge of the product. The stored wheat and silo body interactions were modeled with minimal simplification, taking into account the characteristics of both wheat and steel silo. As a result of the research, the pressure loads in the filling and discharge conditions for both silo models increased from the top of the silo to the discharge opening. It has been determined that lower wall thicknesses are subjected to more pressure load under filling and discharge conditions. While the maximum pressure loads occurred in the funnel area in Silo 1, they occurred in the transition zone in Silo 2. As a result of ANSYS simulation, the maximum deformations for both silo models were determined in the transition zone and just below this zone. According to the results of the modal analysis, it was observed that the frequency values increased with the increase of silo wall thickness. In the light of these data, it can be said that safe and secure storage is Silo 1 and $8 \mathrm{~mm}$ wall thickness.
\end{abstract}




\section{GíRiş}

Silolar, en az bozulma ile tarım ve gıda ürünlerinin uzun süreli muhafazasında etkili olan kontrollü depolama yapılarıdır. Bu yapılar genellikle çelik veya betondan yapılmakta ve geleneksel torba saklama sistemine bir alternatif olarak kabul edilmektedir. Bu yapıların imalatında yer alan yüksek başlangıç maliyeti, küçük ve orta gelire sahip çiftçiler tarafından benimsenmesi büyük bir engeldir. Son yıllarda dünya çapında düşük maliyetli, çevresel olarak sürdürülebilir silo yapıları geliştirilmiştir (Jayachandran ve ark., 2019).

İyileştirilmiş tahıl depolama yapılarının tasarımı ve geliştirilmesi, yapısal güvenlikleri ve fonksiyonel etkinlikleri hakkında yeterli bilgi düzeyine sahip olmayı gerektirmektedir. Tanecikli malzemenin doldurulması ve boşaltılması sırasında silolarda oluşan gerilmeler oldukça karmaşıktır. Bu karmaşık depolama işlemlerinin dinamikleri genellikle teorik (Janssen, 1895; Reimbert ve Reimbert, 1987; Walker ve Blanchard, 1967), analitik (BIS, 1974; ACl, 1997; Eurocode 1, 2003; CEN, 2007) ve deneysel tekniklerle (Horabik ve Molenda, 2017; Wojcik ve ark., 2017) sık sık tanımlanmıştır.

Deneysel analiz ve testler en güvenilir yöntem olsa da, prototip / tam ölçekli siloların kurulmasında, enstrümantasyon ve sensörlerin kurulumundan kaynaklanan geometrik hatalar büyük masraflar ortaya çıkarmaktadır. Bu nedenle, birkaç silo araştırmacısı klasik teorilere ve tasarım standartlarına güvenerek tasarım gerçekleştirmiştir. Bu teoriler ve standartlar, depolanmış tahılların statik durumunu açıklamak için geliştirilmiştir ve doldurma ve boşaltma koşullarında oluşan dinamik gerilmeleri hesaba katmak için basınç katsayısı kullanmıştır. Janssen'in ve Reimbert'in teorisi, tahıl silolarının yapısal analizinde en popüler iki teoridir. Bu teorilerin sonuçlarında, özellikle malzeme parametreleri teorik bir sınırlama değerine yaklaştığında, önemli farklılıklarla karşılaşılmıştır. Birçok çalışma, Janssen teorisinin, kritik sınırlayıcı durumlarda Reimbert'in teorisine üstünlük sağladığını ileri sürmektedir (Manbeck ve ark., 1995). Tahılların depolanması için tasarlanan çelik siloların tasarımı için Avrupa Birliği tarafından Eurocode standartlarının kullanılması önerilmektedir. Eurocode standardı, doldurma ve boşaltma koşulları altında çeşitli basınç yüklerinin hesaplanması için depolanacak ürüne özgü birim hacim ağırlığı (yığın yoğunluğu), içsel sürtünme açısı, cidar sürtünme katsayısı ve basınç oranı gibi teknolojik özellik değerlerini kullanmaktadır. Basınç hesaplamaları, silo sistemindeki üç farklı yük türünü (yatay, düşey ve sürtünme çekmesi yükleri) tahmin eden depolanmış malzeme özelliklerine dayanmaktadır.

Sonlu Elemanlar Yöntemi (FEM) gibi sayısal tekniklerin ortaya çıkışı, depolanmış tahıllar ile silo cidarı arasındaki karmaşık etkileşimleri ortaya koymak için yeni çözüm yollarının geliştirilmesine olanak sağlamıştır. Yapılan çalışmalar, sonlu elemanlar yöntemi'nin silo gerilimlerini tahmin etmede daha kesin sonuçlar ortaya koyduğunu göstermiştir (Rotter ve ark., 1998). Son yıllarda, FEM, tahıl silolarının ve depolanan ürünün yapısal davranışının tahmin edilmesi konusunda ümit verici bir teknik olarak gelişmiştir. Çok yönlülük ile karakterize edilen FEM, silo gerilimlerini analiz etmenin ekonomik bir yolu olarak kurulmuştur. Ayrıca, FEM, geleneksel teorileri kullanarak başka türlü imkansız olan çok çeşitli karmaşık silo olaylarının başarıyla çözümünü gerçekleştirmiştir. Bunlar eksantrik boşaltma (Vidal ve ark., 2008; Lapko, 2010), aşamalı ve toplu doldurma (Gallego ve ark., 2010), esnek cidarlı silolar (Guines ve ark., 2001), düz ve eğimli silo tabanlarından (Goodey ve Brown, 2004) ve düz ve huni tabanlarından kaynaklanan geometrik kusurlardır (Guaita ve ark., 2003; Zheng ve Yu, 2015).

Depolanan ürüne bağlı olarak değişen mekanik özelliklerin silolar üzerinde oluşturduğu yüklerin etkisinin ortaya çıkması ile yaygın olarak depolanan ürünlerin mekanik özelliklerini belirlemek için deneysel çalışmalar yapılmıştır (Kibar, 2016; Kibar ve Kibar, 2017; Kibar ve Kibar, 2019). Bununla birlikte, biyolojik materyallerin yetiştirilme koşullarına bağlı olarak ortaya çıkan özellikleri nadiren sabit bir değer kazanmakta ve yetiştirilme şekli, ürün nem içeriği ve ürünün olgunluğuna göre farklılık gösterebilmektedir. Bu nedenle, depolanan ürünlerin farklı mekanik özellikleri üzerine geliştirilen FEM modelinin duyarlıığının doğrulanması gerekmektedir.

Bu çalışmanın birinci amacı buğdayın uzun süre güvenli bir şekilde depolanması için tasarlanmış çelik konstrüksiyon silonun yapısal performansını doldurma ve boşaltma koşullarına bağlı olarak FEM tabanlı ANSYS yazılımı ile araştırmaktır. İkinci amacı ise farklı depolama kapasiteleri (1306 ton ve 610 ton) ve cidar kalınlıklarına sahip iki tip model silonun (Silo 1 ve 2) her biri için cidar kalınlığının $(3,4,5,6,7,8$, 9 ve 10 mm) değiştirilmesine bağlı olarak farklı simülasyonlar ile cidar üzerindeki deformasyon durumlarını incelemektir.

\section{MATERYAL VE METOT}

Araştırma alanı olarak $39^{\circ} 55^{\prime} 51^{\prime \prime}$ ve $44^{\circ} 08^{\prime} 40^{\prime \prime}$ matematik konuma sahip Iğdır ili seçilmiş̧tir. Araştırmada Iğdır ilinde yaygın olarak yetiştiriciliği yapılan ürünlerden biri olan buğday tahılı depolanacak ürün olarak seçilmiştir. Ayrıca bu ürünün işleme ve ihracat süresince depolama gereksiniminin ortaya çıkması bu ürünün seçilmesinde de etkili olmuştur. Bu kapsamda Iğdır ilinde hasat edilen buğdayın hasat sonrası güvenli bir şekilde depolanabilmesi için silindirik gövdeli ve konik çıkış ağızlı çelik konstrüksiyon model silolar projelendirilmiştir. Bu amaçla iki adet 
model silo ele alınmıştır. Bu silo modellerine ilişkin özellikler Çizelge 1 ve Şekil 1'de verilmiştir. Çalışmada ticari olarak işletilen silolar gözönüne alınarak silo boyutları ve depolama kapasiteleri belirlenmiştir. Seçilen boyutlara bağlı olarak 1306 ve 610 ton depolama kapasitesine sahip iki adet model silo tasarlanmıştır. Tasarımı yapılan silolarda depolanan buğday tahılı ile ilgili mekanik özellikler Çizelge 2'de verilmiştir.

Çizelge 1. Tasarımı yapılan siloların yapısal özellikleri.

Table 1. Structural properties of designed silos.

\begin{tabular}{|c|c|c|}
\hline Model & Boyutsal özellikler & Konstrüksiyon malzemesi özellikleri \\
\hline Silo 1 & $\begin{array}{l}\mathrm{d}_{\mathrm{c}}: 10 \mathrm{~m} \\
\mathrm{~h}_{\mathrm{c}}: 20 \mathrm{~m} \\
\mathrm{~h}_{\mathrm{b}}: 23 \mathrm{~m} \\
\mathrm{~h}_{\mathrm{h}}: 3 \mathrm{~m} \\
\mathrm{r} \quad: 5 \mathrm{~m} \\
\mathrm{t} \quad: 3,4,5,6,7,8,9,10 \mathrm{~mm} \\
\alpha \quad: 30^{\circ} \\
\beta \quad: 60^{0} \\
\mathrm{~V}_{\mathrm{s}}: 1306 \text { ton } \\
\text {-Kesit geometrisine göre silo tipi: } \mathrm{h}_{\mathrm{c}} / \mathrm{d}_{\mathrm{c}}=20 / 10= \\
2.0 \geq 2.0 \text { olduğundan narin silodur. } \\
\text {-Etki Değer Sınıfi: Silolanacak ürün miktarı yaklaşık } \\
1306 \text { ton'dur. Buna göre } 1306 \text { ton }<10.000 \text { ton } \\
\text { olduğundan etki değer sınıfı } 2 \text { 'dir (EDS=2). } \\
\text {-Huni tipi: tan60<(1-0.52)/(2x0.368) koşulunu } \\
\text { sağlanmadığından sığ hunidir. }\end{array}$ & $\begin{array}{l}\text { - Gövde malzemesi: } \\
\text { Galvaniz kaplı karbon S235 çeliği (D2) } \\
\text { Elastisite modülü } \quad: 2.1 \times 10^{8} \mathrm{kPa}\end{array}$ \\
\hline Silo 2 & $\begin{array}{l}\mathrm{d}_{\mathrm{c}}: 8 \mathrm{~m} \\
\mathrm{~h}_{\mathrm{c}}: 14 \mathrm{~m} \\
\mathrm{~h}_{\mathrm{b}}: 18 \mathrm{~m} \\
\mathrm{~h}_{\mathrm{h}}: 4 \mathrm{~m} \\
\mathrm{r} \quad: 4 \mathrm{~m} \\
\mathrm{t} \quad: 3,4,5,6,7,8,9,10 \mathrm{~mm} \\
\alpha \quad: 45^{0} \\
\beta \quad: 45^{\circ} \\
\mathrm{V}_{\mathrm{s}}: 610 \text { ton } \\
\text {-Kesit geometrisine göre silo tipi: } \mathrm{h}_{\mathrm{c}} / \mathrm{d}_{\mathrm{c}}=14 / 8= \\
1.75 \text { 'dir. Buna göre } 1.0<\mathrm{h}_{\mathrm{c}} / \mathrm{d}_{\mathrm{c}}<2.0 \text { olduğundan orta } \\
\text { derecede ince uzun silodur. } \\
\text {-Etki Değer Sınıfı: Silolanacak ürün miktarı yaklaşık } 610 \\
\text { ton'dur. Buna göre } 610 \text { ton }<10.000 \text { ton olduğundan } \\
\text { etki değer sınıfı 2'dir }(\mathrm{EDS}=2) . \\
\text {-Huni tipi: tan45<(1-0.52)/(2x0.368) koşulunu } \\
\text { sağlanmadığından sığ hunidir. }\end{array}$ & $\begin{array}{ll}\text { Birim ağırlık } & : 78.5 \mathrm{kN} \mathrm{m}^{-3} \\
\text { Akma dayanımı } & : 235000 \mathrm{kPa} \\
\text { Hesap akma dayanımı } & : 188000 \mathrm{kPa} \\
\text { Kayma modülü } & : 81000 \mathrm{kPa} \\
\text { - Birleştirmeler } \quad: \text { Bulon }\end{array}$ \\
\hline
\end{tabular}

Çizelge 2. Depolanan buğday tahılı ile ilgili teknolojik özellikler.

Table 2. The technological properties related to stored wheat grain.

\begin{tabular}{lll}
\hline Özellikler & Birim & Değer \\
\hline Birim hacim ağırlı̆̆ı, $\gamma_{m}$ & $\mathrm{kN} \mathrm{m}^{-3}$ & 7.92 \\
İçsel sürtünme açısı, $\varphi_{\mathrm{m}}$ & derece & $28.4^{\circ}$ \\
Statik sürtünme katsayısı, $\mu_{m}$ & & 0.405 \\
Basınç oranı, $K_{m}$ & & 0.58 \\
\hline
\end{tabular}

Silo cidarına etki eden tasarım yüklerinin belirlenmesinde Eurocode 1 (2003) (Yapıların Projelendirme ve Etki Esasları, Bölüm: 4 Silo ve Tank Etkileri) standarı temel alınmıştır. Araştırmada bu standardın seçilmesindeki temel yaklaşım Eurocode 1'in geniş bir perspektifte kullanılması ve farklı projeleme esaslarını temel almasıdır.

Silo modellerine etki eden basınç yüklerinin hesaplanmasında kullanılan Eurocode 1 (2003) standardına ilişkin temel denklemler Kibar (2011)'de ayrıntılı olarak açıklandığından araştırma çalışmasında tekrar verilmemiştir. Basınç yükleri her iki silo modeli için hem doldurma hemde boşaltma koşullarına göre ayrı ayrı hesaplanmıştır. Denklemlere bağlı olarak hesaplanan basınç yüklerinin FEM tabanlı ANSYS 14.0 yazılımı ile simülasyonları yapılmıştır. Simülasyonların sonucunda silo cidarı üzerinde oluşan gerilmelerin karşılaştırmalı analizleri yapılmıştır. 
Çalışmada kullanılan silo cidar malzemesinin temel özellikleri, Eurocode 3'te belirtilen çelik yapıların tasarım standardına göre belirlenmiştir (Eurocode 3, 2004). Cidar malzemesi olarak siloların tasarımında ve bilimsel araştırmalarda yaygın olarak kullanılan S235 çeliği, Vidal ve ark. (2004), Ayuga ve ark. (2006), Vidal ve ark. (2006) tarafından yapılmış çalışmalar da göz önüne alınarak seçilmiştir. Seçilen cidar malzemesinin temel özellikleri ise Çizelge 1'de verilmiştir.

Çalışmada ANSYS programında yapısal (structural) analiz kullanılmıştır. Tasarlanan her iki silo modeli metre $(\mathrm{m})$ ve kiloPascal $(\mathrm{kPa})$ birimleri ile ANSYS ön işlemcisi kullanılarak oluşturulmuştur. Silo modelleri için eleman tipi olarak ANSYS (2013) eleman kütüphanesinden SHELL63 eleman tipi kullanılmıştır (Şekil 2). Ön analizler sonucunda kullanılan S235 çeliğinin karakteristik özelliklerini en iyi yansıtması ve en iyi sonuçlar bu eleman tipinde belirlendiğinden eleman olarak SHELL63 kullanılmıştır.

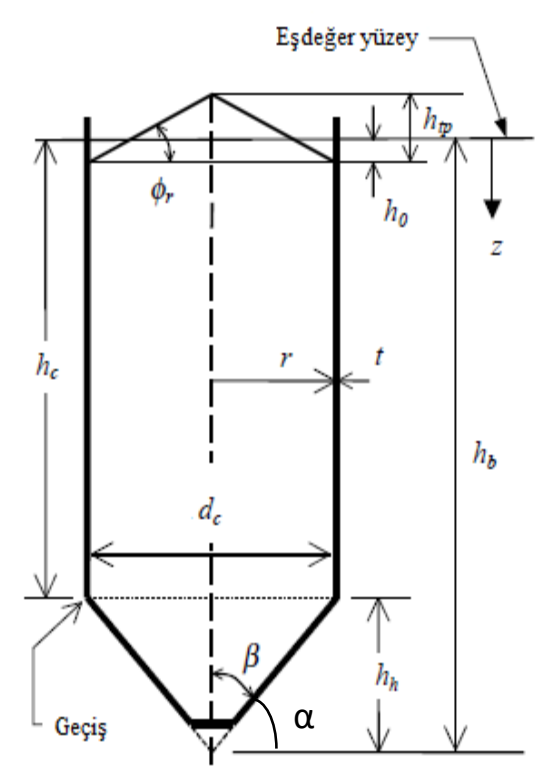

Şekil 1. Silo kesit geometrisi.

Figure 1. Cross-sectional geometry of the silo. $\boldsymbol{d}_{\boldsymbol{c}}$ : Silo çapı, $\mathrm{m}$

$\boldsymbol{h}_{\boldsymbol{c}}$ : Geçiş ile eşdeğer yüzey arasındaki düşey mesafe, $\mathrm{m}$

$\boldsymbol{h}_{\boldsymbol{b}}$ : Çıkış apeksinden eşdeğer yüzeye olan mesafe, $\mathrm{m}$ $\boldsymbol{h}_{\boldsymbol{h}}$ : Geçiş bölgesi ile apeks arasındaki huni yüksekliği, $\mathrm{m}$ $\boldsymbol{h}_{\boldsymbol{o}}$ : Üst yığın tabanında eşdeğer yüzeyin altındaki derinlik, $m$

$\boldsymbol{h}_{t p}$ : Silo üst kısmındaki şev yüksekliği, m

$\boldsymbol{r}$ : Silo eşdeğer yarıçapı $\left(r=0.5 \mathrm{~d}_{c}\right), \mathrm{m}$

$\boldsymbol{t}$ : Silo cidar kalınlığı, $\mathrm{mm}$

$\boldsymbol{z}$ : Ortalama doldurma düzlemi (eşdeğer yüzey)'ne göre derinlik, $m$

$\boldsymbol{\alpha}$ : Ortalama huni eğim açısı (yatayla yapılan açı), derece

$\boldsymbol{\beta}$ : Düşeyden ölçülen silo duvarı eğim açısı, Huni apex yarı açısı $\left(=90^{\circ}-\alpha\right)$

$\boldsymbol{\varphi}_{r}$ : Silolanan malzeme şev açısı, derece
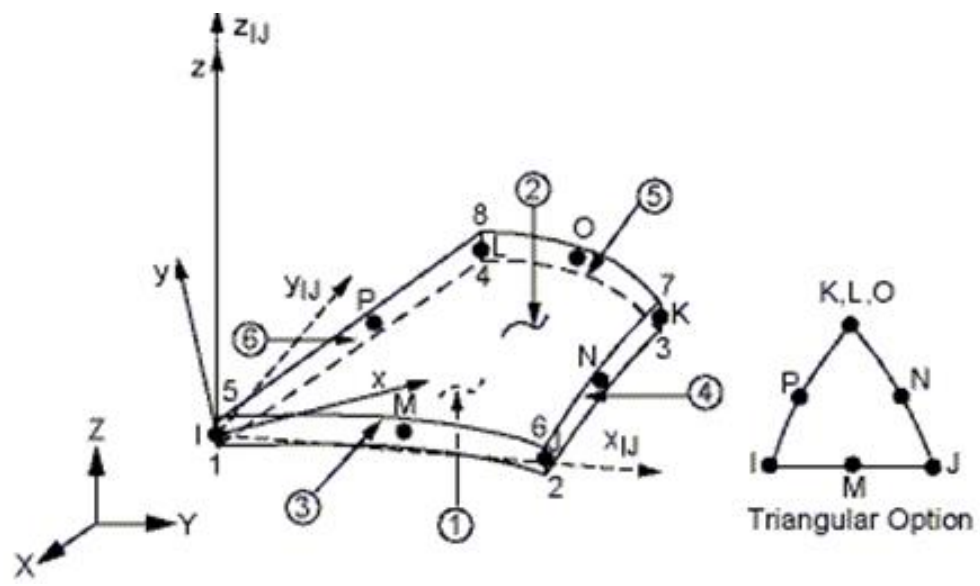

Şekil 2. SHELL63 eleman için geometri.

Figure 2. Geometry for SHELL63 element.

Silonun elemanlara bölünmesi model sürekliliğinin belirli sayıdaki ayrı parçalara diğer bir ifade ile sonlu elemanlara bölünmesidir. Modellenen silonun elemanlara (mesh) ayrılmış görünümü ve mesnet noktaları Şekil 3'te verilmiştir. 

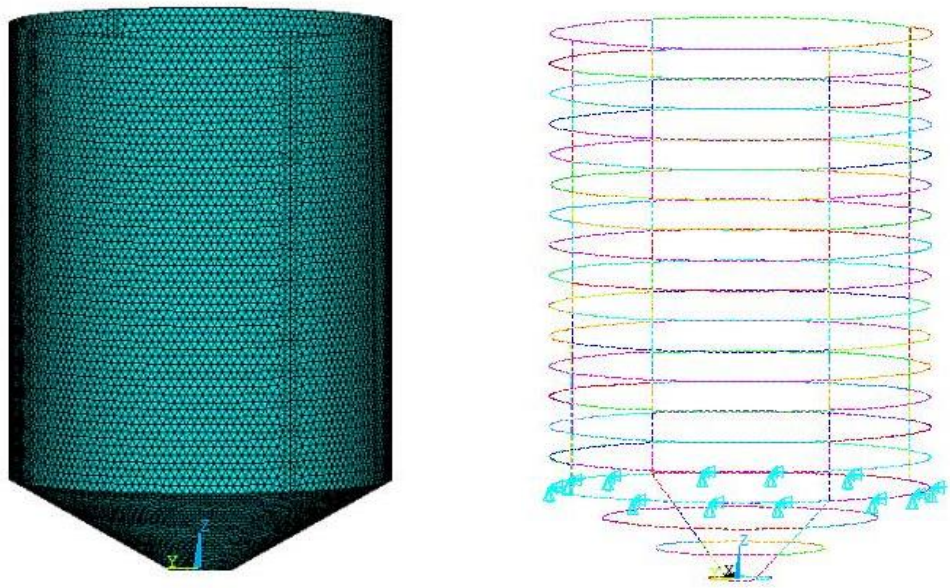

Şekil 3. Modellenen silonun elemanlara ayrılması ve mesnet noktaları.

Figure 3. The elements (mesh) separation and support points of modeled silo.

\section{BULGULAR}

\section{Modal Analiz Sonuçlarının Değerlendirilmesi}

ANSYS sonlu eleman programı ile yapılan modal analiz sonucunda Silo 1 ve 2'nin 8 farklı cidar kalınlıklarına ilişkin 10 doğal frekans değeri Çizelge 3'te verilmiştir. Çizelge 3 incelendiğinde doğal frekansların Silo 1 için 0.35 $0.76 \mathrm{~Hz}$. ve Silo 2 için ise 0.21-0.70 Hz. arasında değiştiği görülmektedir. Silo 1 ve 3 mm cidar kalınlığı için yapılan analizler sonucunda ANSYS eleman kütüphanesi içerisinden farklı cidar malzeme türleri (SHELL41, 43, 61, 150) kullanılmasına karşın cidar kalınlığının çok ince olmasından dolayı ANSYS sonlu eleman programından herhangi bir sonuç alınamamıştır. Her iki silonun farklı cidar kalınlıkları için doğal frekans değerleri incelendiğinde, cidar kalınlığı arttıkça doğal frekans değerinin arttığı, bu durumda silonun olası zemin titreşimlerine karşı daha güçlü davranacağı söylenebilir.

Çizelge 3. Farklı cidar kalınlıklarında Silo 1 ve 2 için doğal frekanslar.

Table 3. Natural frequencies for Silos 1 and 2 in different wall thicknesses.

\begin{tabular}{llllllllll}
\hline & Mod & & \multicolumn{7}{c}{ Doğal frekans (Hz.) } \\
& No & $\mathbf{3}$ & $\mathbf{4}$ & $\mathbf{5}$ & $\mathbf{6}$ & $\mathbf{7}$ & $\mathbf{8}$ & $\mathbf{9}$ & $\mathbf{1 0}$ \\
\hline & 1 & - & 0.3539 & 0.4057 & 0.4241 & 0.4613 & 0.4922 & 0.5355 & 0.5684 \\
& 2 & - & 0.3558 & 0.4086 & 0.4288 & 0.4664 & 0.4933 & 0.5384 & 0.5696 \\
& 3 & - & 03678 & 0.4156 & 0.4452 & 0.4851 & 0.5320 & 0.5475 & 0.5812 \\
& 4 & - & 0.3692 & 0.4193 & 0.4469 & 0.4889 & 0.5341 & 0.5489 & 0.5873 \\
Silo 1 & 5 & - & 0.3817 & 0.4218 & 0.4602 & 0.4959 & 0.5417 & 0.6441 & 0.6645 \\
& 6 & - & 0.3889 & 0.4256 & 0.4654 & 0.4997 & 0.5428 & 0.6459 & 0.6663 \\
& 7 & - & 0.3907 & 0.4279 & 0.4691 & 0.5088 & 0.5476 & 0.6488 & 0.6689 \\
& 8 & - & 0.4073 & 0.4314 & 0.4803 & 0.5458 & 0.6621 & 0.7103 & 0.7459 \\
& 9 & - & 0.4098 & 0.4375 & 0.4859 & 0.5499 & 0.6689 & 0.7147 & 0.7490 \\
& 10 & - & 0.4188 & 0.4419 & 0.4941 & 0.5863 & 0.6874 & 0.7311 & 0.7621 \\
\hline & 1 & 0.2123 & 0.2456 & 0.2778 & 0.2941 & 0.3218 & 0.3643 & 0.4103 & 0.4551 \\
& 2 & 0.2174 & 0.2488 & 0.2797 & 0.2989 & 0.3257 & 0.3684 & 0.4176 & 0.4586 \\
& 3 & 0.2346 & 0.2541 & 0.2902 & 0.3002 & 0.3307 & 0.3727 & 0.4311 & 0.4922 \\
& 4 & 0.2384 & 0.2546 & 0.2940 & 0.3056 & 0.3366 & 0.3766 & 0.4358 & 0.4964 \\
Silo 2 & 5 & 0.2398 & 0.2587 & 0.2969 & 0.3097 & 0.3397 & 0.3794 & 0.4389 & 0.4983 \\
& 6 & 0.2556 & 0.2869 & 0.3114 & 0.3309 & 0.3613 & 0.4004 & 0.4569 & 0.5517 \\
& 7 & 0.2592 & 0.2897 & 0.3188 & 0.3387 & 0.3679 & 0.4068 & 0.4599 & 0.5582 \\
& 8 & 0.2774 & 0.2956 & 0.3356 & 0.3517 & 0.3841 & 0.4254 & 0.4723 & 0.6514 \\
& 9 & 0.2794 & 0.2976 & 0.3397 & 0.3588 & 0.3883 & 0.4283 & 0.4768 & 0.6576 \\
& 10 & 0.2853 & 0.3108 & 0.3507 & 0.3964 & 0.4255 & 0.4619 & 0.5137 & 0.7081 \\
\hline
\end{tabular}

\section{Silo 1 ve Silo 2'nin Cidarı Üzerinde Meydana Gelen Basınçlar}

Eurocode 1'e bağlı olarak buğday tahılı için oluşturulan Silo 1 ve Silo 2'nin farklı yüksekliklere bağlı doldurma ve boşaltma koşullarındaki basınç değişimleri Çizelge 4 ve 5 'te verilmiştir. Çizelgeler incelendiğinde yükseklik azaldıkça her iki silo tipinde farklı koşullarda basınç artışları meydana gelmiştir. Ancak silonun çıkış ağzına doğru basınç azalmaya başlamış ve huni çıkışında sıfır olarak gerçekleşmiştir. Özellikle Silo 1 için maksimum basınç yükleri huni bölgesinde meydana gelmiştir. Dolayısıyla bu bölgelerde daha fazla zorlanmanın olacağı söylenebilir. 
Silo 2'de ise doldurma ve boşaltma koşullarında maksimum basınç yük değerleri geçiş bölgesinde ortaya çıkmıştır. Silo 2 olarak ifade edilen orta derecede ince uzun siloda sadece doldurma yükleri hesaplanmış boşaltma yükleri ise hesaplanmamıştır. Bu durum çalışmada kullanılan Eurocode 1 standardında doldurma yükleri ile boşaltma yüklerinin hesaplanma kriterlerinin aynı olmasından kaynaklanmaktadır.

Çizelge 4. Farklı yüksekliklerde Silo 1 cidarı üzerindeki basınç yüklerinin değişimi. Table 4. Variation of pressure loads on Silo 1 wall at different heights.

\begin{tabular}{|c|c|c|c|c|c|}
\hline \multirow{2}{*}{$\begin{array}{l}\text { Silo yüksekliği } \\
\text { (m) }\end{array}$} & \multicolumn{3}{|c|}{ Doldurma yükleri } & \multicolumn{2}{|c|}{ Boşaltma yükleri } \\
\hline & $\begin{array}{l}\text { Yatay basınç } \\
(\mathrm{kPa})\end{array}$ & $\begin{array}{l}\text { Düşey basınç } \\
(\mathrm{kPa})\end{array}$ & $\begin{array}{l}\text { Sürtünme çekmesi } \\
(\mathrm{kPa})\end{array}$ & $\begin{array}{l}\text { Yatay basınç } \\
(\mathrm{kPa})\end{array}$ & $\begin{array}{l}\text { Sürtünme } \\
\text { çekmesi (kPa) }\end{array}$ \\
\hline 23 & 0.00 & 0.00 & 0.00 & 0.00 & 0.00 \\
\hline 22 & 5.28 & 8.24 & 2.33 & 6.07 & 2.56 \\
\hline 21 & 10.09 & 15.59 & 4.41 & 11.60 & 4.85 \\
\hline 20 & 14.47 & 22.16 & 6.27 & 16.64 & 6.89 \\
\hline 19 & 18.46 & 28.03 & 7.93 & 21.22 & 8.72 \\
\hline 18 & 22.09 & 33.27 & 9.41 & 25.40 & 10.35 \\
\hline 17 & 25.40 & 37.95 & 10.73 & 29.21 & 11.80 \\
\hline 16 & 28.41 & 42.13 & 11.91 & 32.67 & 13.10 \\
\hline 15 & 31.15 & 45.86 & 12.97 & 35.83 & 14.27 \\
\hline 14 & 33.65 & 49.19 & 13.91 & 38.70 & 15.30 \\
\hline 13 & 35.93 & 52.17 & 14.75 & 41.32 & 16.23 \\
\hline 12 & 38.00 & 54.83 & 15.50 & 43.70 & 17.05 \\
\hline 11 & 39.89 & 57.20 & 16.18 & 45.87 & 17.79 \\
\hline 10 & 41.61 & 59.32 & 16.77 & 47.85 & 18.45 \\
\hline 9 & 43.17 & 61.21 & 17.31 & 49.65 & 19.04 \\
\hline 8 & 44.60 & 62.90 & 17.79 & 51.29 & 19.57 \\
\hline 7 & 45.90 & 64.41 & 18.22 & 52.79 & 20.04 \\
\hline 6 & 47.08 & 65.76 & 18.60 & 54.15 & 20.46 \\
\hline 5 & 48.16 & 66.97 & 18.94 & 55.38 & 20.83 \\
\hline 4 & 49.14 & 68.04 & 19.24 & 56.51 & 21.16 \\
\hline 3 & 76.36 & 89.55 & 28.11 & 76.88 & 28.30 \\
\hline 2 & 57.00 & 67.48 & 20.99 & 57.39 & 21.13 \\
\hline 1 & 33.66 & 49.86 & 12.39 & 33.89 & 12.48 \\
\hline
\end{tabular}

Çizelge 5. Farklı yüksekliklerde Silo 2 cidarı üzerindeki basınç yüklerinin değişimi. Table 5. Variation of pressure loads on Silo 2 wall at different heights.

\begin{tabular}{|c|c|c|c|}
\hline \multirow{2}{*}{$\begin{array}{l}\text { Silo yüksekliği } \\
\text { (m) }\end{array}$} & \multicolumn{3}{|c|}{ Doldurma yükleri } \\
\hline & $\begin{array}{l}\text { Yatay basınç } \\
(\mathrm{kPa})\end{array}$ & $\begin{array}{l}\text { Düşey basınç } \\
(\mathrm{kPa})\end{array}$ & $\begin{array}{l}\text { Sürtünme çekmesi } \\
(\mathrm{kPa})\end{array}$ \\
\hline 18 & 0.00 & 0.00 & 0.00 \\
\hline 17 & 1.36 & 1.17 & 0.61 \\
\hline 16 & 12.22 & 8.70 & 5.44 \\
\hline 15 & 19.71 & 16.10 & 8.78 \\
\hline 14 & 25.10 & 21.83 & 11.18 \\
\hline 13 & 29.08 & 26.39 & 12.96 \\
\hline 12 & 32.11 & 30.10 & 14.30 \\
\hline 11 & 34.46 & 33.17 & 15.35 \\
\hline 10 & 36.31 & 35.74 & 16.18 \\
\hline 9 & 37.81 & 37.93 & 16.84 \\
\hline 8 & 39.02 & 39.82 & 17.38 \\
\hline 7 & 40.03 & 41.46 & 17.83 \\
\hline 6 & 40.86 & 42.89 & 18.20 \\
\hline 5 & 41.57 & 44.15 & 18.52 \\
\hline 4 & 51.40 & 53.84 & 18.92 \\
\hline 3 & 50.93 & 52.44 & 18.75 \\
\hline 2 & 47.37 & 48.26 & 17.44 \\
\hline 1 & 38.09 & 41.12 & 14.02 \\
\hline
\end{tabular}




\section{Doldurma Koşullarında Gerilme Sonuçlarının Değerlendirilmesi}

Silo 1 ve 2'ye ilişkin 3, 4, 5, 6, 7, 8, 9 ve 10 mm cidar kalınlıklarına doldurma koşullarında yatay basınç yükünün uygulanmasıyla elde edilen von Mises gerilmeleri Çizelge 6 'da ve von Mises gerilme dağılımları Ek 1 ve 2'de verilmiş̧ir. Çizelge 6 incelendiğinde Silo 1 için $3 \mathrm{~mm}$ cidar kalınlığında ANSYS analizi sonucunda herhangi bir değer elde edilememesine karşın Silo 2 için $3 \mathrm{~mm}$ cidar kalınlığında sonuç elde edilmiştir. Burada temel sorun Silo 1'in kapasitesinin 1306 ton olması ve buna bağlı olarak 3 mm cidar kalınlığının çok ince olmasıdır. Ancak Silo 2'nin kapasitesi 610 ton olduğundan 3 mm cidar kalınlığında ANSYS simülasyonları ile sonuç alınmıştır.

Çizelge 6 ve Ek 1 incelendiğinde gerilmelerin huninin merkezinde yoğunlaştığı ve maksimum gerilme değerinin $287321 \mathrm{kPa}$ ile $4 \mathrm{~mm}$ cidar kalınlığında olduğu görülmektedir. Ek 1'de 4 mm kalınlıktaki siloda gerilmelerin huninin kenar bölgelerinde ve geçişe yakın kısımlarda oluştuğu ayrıca geçiş bölgesinin hemen altında hunide çökmenin olduğu gözlemlenmiştir. Ek olarak diğer cidar kalınlıklarında ise yine gerilme değişimlerinin daha çok huni bölgesinde oluştuğu saptanmıştır. Silo1 için 4, 5 ve $6 \mathrm{~mm}$ cidar kalınlıklarının von Mises gerilme değerleri incelendiğinde bu değerlerin çeliğin hesap akma dayanımı olan $188000 \mathrm{kPa}$ (Çizelge 1) değerinden büyük olması nedeniyle doldurma koşullarında yatay basınç yükünün neden olduğu bu gerilmeler açısından emniyetli olmadığı tespit edilmiştir. 7, 8, 9 ve 10 mm cidar kalınlıklarının emniyetli oldukları Çizelge 6'dan görülmektedir.

Silo 2 ve Ek 2'nin incelenmesiyle cidar kalınlıklarının artması ile von Mises gerilme değerlerinin azaldığı belirlenmiştir. Silo çıkışına yakın ve silindirik bölgelerde ise gerilmelerin en düşük olduğu saptanmıştır. 3 ve $4 \mathrm{~mm}$ cidar kalınlıklarında ise huniye geçiş bölgesinin hemen altında çökmeler tespit edilmiştir. Bunlara bağlı olarak 3 , 4, 5 ve 6 mm cidar kalınlıklarının von Mises gerilme değerleri sırasıyla 314567, 284147, 250041 ve $189893 \mathrm{kPa}$ olarak elde edilmiştir (Çizelge 6). Bu değerler 188000 kPa'ık çelik hesap akma dayanım değerinden büyük olduğundan belirtilen cidar kalınlıkları emniyetsiz olup 7, 8, 9 ve 10 mm'lik kalınlıkların doldurma koşullarında yatay basınç yükü açısından emniyetli oldukları belirlenmiştir.

Çizelge 6. Doldurma koşullarında yatay basınç yüküne bağı gerilme değişimleri. Table 6. The stress changes due to horizontal pressure load in filling conditions.

\begin{tabular}{lll}
\hline & Silo cidar kalınlığı $(\mathbf{m m})$ & von Mises gerilmesi $\mathbf{( k P a )}$ \\
\hline 3 & - \\
Silo 1 & 4 & 287321 \\
& 5 & 211264 \\
& 6 & 190845 \\
& 7 & 181056 \\
& 8 & 155214 \\
9 & 101308 \\
& 10 & 89358 \\
\hline & 3 & 314567 \\
& 4 & 284147 \\
& 5 & 250041 \\
& 6 & 189893 \\
& 7 & 165921 \\
& 8 & 141087 \\
9 & 10 & 133017 \\
\hline
\end{tabular}

Doldurma koşullarında buğday silosu için Silo 1 ve 2'ye ilişkin düşey basınç değerlerine bağlı von Mises gerilmeleri Çizelge 7'de ve von Mises gerilmelerinin silo üzerindeki dağılımları Ek 3 ve 4'te verilmiştir. Silo 1'e ait gerilme değerleri $324698 \mathrm{kPa}$ ile $121212 \mathrm{kPa}$ arasında değişim göstermiştir. 3 mm'lik cidar kalınlığının analizi sonucunda herhangi bir sonuç alınamamıştır. Diğer cidar kalınlıklarındaki gerilme değerleri incelendiğinde 4, 5, 6 ve $7 \mathrm{~mm}$ cidar kalınlıkları için elde edilen gerilme değerleri çeliğin hesap akma dayanımı olan $188000 \mathrm{kPa}$ değerinden büyük olduğundan emniyetsiz oldukları belirlenmiştir. Ek 3'te verilen gerilme dağılım grafikleri incelendiğinde $4 \mathrm{~mm}$ cidar kalınlığa ilişkin silonun huni bölgesinde çökmeler meydana gelmiştir. Diğer kalınlıklarda ise hem silindirik bölgede hemde huni bölgesinde gerilme farklılaşmaları gözlemlenmiştir. Silo 2'ye ilişkin farklı cidar kalınlıklarında gerilme değerleri 318569 kPa ile 109062 kPa arasında değişim göstermiştir. Ancak bu gerilme değerlerinden $3 \mathrm{~mm}-6 \mathrm{~mm}$ arasındaki cidar kalınlıklarının gerilmeler yönünden emniyetsiz oldukları saptanmıştır. Diğer kalınlıkların ise emniyetli oldukları belirlenmiştir. Ek 4 incelendiğinde siloların huni bölgelerinde çökmeler meydana gelmiştir. 5, 6, 8 ve $9 \mathrm{~mm}$ cidar kalınlıklarının silindirik bölgesinde silonun tepesine doğru burulmalar gözlemlenmiştir. Burulma durumuna karşın 8 ve $9 \mathrm{~mm}$ kalınlıklar emniyetli durum göstermiştir. 
Çizelge 7. Doldurma koşullarında düşey basınç yüküne bağlı gerilme değişimleri.

Table 7. The stress changes due to vertical pressure load in filling conditions.

\begin{tabular}{lll}
\hline & Silo cidar kalınlığı $\mathbf{( m m})$ & von Mises gerilmesi $\mathbf{( k P a )}$ \\
\hline & 3 & - \\
& 4 & 324698 \\
\multirow{4}{*}{ Silo 1} & 5 & 290014 \\
& 6 & 251039 \\
& 7 & 200322 \\
& 8 & 177096 \\
& 9 & 141548 \\
& 10 & 121212 \\
\hline & 3 & 318569 \\
& 4 & 289113 \\
& 5 & 252563 \\
& 6 & 190124 \\
& 7 & 166123 \\
& 9 & 142005 \\
& 10 & 133213 \\
\hline
\end{tabular}

Buğday için yapılan analiz sonucunda Silo 1 ve 2'de doldurma koşullarında sürtünme çekmesinin neden olduğu gerilmeler Çizelge $8^{\prime}$ de, bu gerilmelerin silo cidarı üzerindeki dağılımları Ek 5 ve 6 'da verilmiştir. Çizelge 8 incelendiğinde diğer koşullarda olduğu gibi Silo 1 için $3 \mathrm{~mm}$ cidar kalınlığında da sonuç alınamamıştır. Diğer tüm cidar kalınlıklarının ise emniyetli olduğu belirlenmiştir. Cidar kalınlığı arttıkça sürtünme çekmesi yükünün neden olduğu gerilmeler azalışlar göstermiştir. Bu durum silonun üzerine gelebilecek gerilmeleri daha kolay karşılayabileceğini göstermektedir. Silo 2'de ise Silo 1'den farklı olarak $3 \mathrm{~mm}$ kalınlıktan sonuç alınmıştır. Bunun nedeni Silo 2'nin Silo 1'e göre daha az depolama kapasitesine sahip olmasıly zorlanmalara daha az maruz kalmasıdır. Silo 2'nin tüm cidar kalınlıkları hesap akma dayanımı ile karşılaştırıldığında emniyetli oldukları belirlenmiştir.

Çizelge 8. Doldurma koşullarında sürtünme çekmesi yüküne bağlı gerilme değişimleri. Table 8. The stress changes due to friction traction load in filling conditions.

\begin{tabular}{lll}
\hline & Silo cidar kalınlığı $\mathbf{( m m})$ & von Mises gerilmesi $\mathbf{( k P a )}$ \\
\hline & 3 & - \\
& 4 & 174112 \\
& 5 & 151023 \\
Silo 1 & 6 & 102784 \\
& 7 & 88695 \\
& 8 & 65238 \\
& 9 & 51421 \\
& 10 & 44327 \\
\hline \multirow{4}{*}{ Silo 2} & 3 & 154698 \\
& 4 & 140852 \\
& 5 & 131214 \\
& 7 & 114852 \\
& 8 & 100045 \\
& 9 & 81456 \\
& 10 & 71236 \\
\hline
\end{tabular}

\section{Boşaltma Koşullarında Gerilme Sonuçlarının Değerlendirilmesi}

Boşaltma koşullarında buğday tahıı silolarına ilişkin yatay basınç ve sürtünme çekmesi yükünün neden olduğu gerilmeler Çizelge 9 ve 10'da bu gerilmelerin dağılımları ise Ek 7 ve 8'de verilmiştir. Çizelgelerden görüldüğü gibi sadece Silo 1 için analizler yapılmış olup Silo 2 için herhangi bir analiz yapılmamıştır. Bu durumun nedeni daha önceki bölümlerde açıklanmıştır. 3 mm cidar kalınlığının analiz sonuçlarına göre yatay basınç yükü yönünden Silo 1 için sonuç elde edilemez iken sürtünme çekmesi yönünden Silo 1'de sonuç elde edilmiştir. Yatay basınç yükü yönünden en yüksek gerilme değeri 4 mm cidar kalınlığında 301456 kPa olarak belirlenirken en düşük gerilme değeri 10 mm cidar kalınlığında $92653 \mathrm{kPa}$ olarak belirlenmiştir. Sürtünme çekmesi yönünden $4 \mathrm{~mm}$ kalınlıkta $176476 \mathrm{kPa}$ olarak belirlenirken en düşük gerilme değeri $10 \mathrm{~mm}$ kalınlıkta $45991 \mathrm{kPa}$ olarak belirlenmiştir. Değerlerden de görüldüğü gibi kalınlık artışı ile gerilme değerleri azalışlar göstermiştir. Yatay basınç yükünün neden olduğu gerilme azalışı \%30.73, sürtünme çekmesi yükünün neden olduğu gerilme azalışı ise \%26.06'dır. Bu 
durum cidar kalınlığı fazla olan siloların oluşabilecek olumsuz koşullara daha dayanıklı olacağını göstermektedir. Ek 7 incelendiğinde $4 \mathrm{~mm}$ cidar kalınlığında hunide çökmeler oluştuğu belirlenirken $5 \mathrm{~mm}$ cidar kalınlığının silindirik bölgesinde burulmalar meydana gelmiştir. Bu durumlar buğdayın uyguladığı basınç yükü nedeniyle aşırı zorlanmalardan dolayı meydana gelmiştir. Benzer burulma durumları Ek 8'de sürtünme çekmesinin basınç yükü nedeniyle de saptanmıştır.

Çizelge 9. Boşaltma koşullarında yatay basınç yüküne bağlı gerilme değişimleri.

Table 9. The stress changes due to horizontal pressure load in discharge conditions.

\begin{tabular}{lll}
\hline & Silo cidar kalınlığı $(\mathbf{m m})$ & von Mises gerilmesi $\mathbf{( k P a )}$ \\
\hline & 3 & - \\
& 4 & 301456 \\
& 5 & 245123 \\
\multirow{4}{*}{ Silo $\mathbf{1}$} & 6 & 200236 \\
& 7 & 185019 \\
& 8 & 161257 \\
& 9 & 108174 \\
& 10 & 92653 \\
\hline
\end{tabular}

Çizelge 10. Boşaltma koşullarında sürtünme çekmesi yüküne bağlı gerilme değişimleri. Table 10. The stress changes due to friction traction load in discharge conditions.

\begin{tabular}{lll}
\hline & Silo cidar kalınlığı $\mathbf{( m m )}$ & von Mises gerilmesi $\mathbf{( k P a )}$ \\
\hline & 3 & - \\
& 4 & 176476 \\
& 5 & 152632 \\
\multirow{4}{*}{ Silo 1} & 6 & 102985 \\
& 7 & 89187 \\
& 8 & 67456 \\
& 9 & 53498 \\
& 10 & 45991 \\
\hline
\end{tabular}

\section{TARTIŞMA}

Tarımsal üretimde ekonomik dengelere olumsuz etkide bulunabilecek rekolte ve fiyat dalgalanmalarının önüne geçilebilmesi, ancak hasat edilen ürünlerin mühendislik yönünden uygun tasarlanıp projelendirilmiş depolarda pazar değerini koruyuncaya kadar muhafazasıyla olasıdır. Bu durumda üretim kadar hasat edilen ürünün muhafazası da son derece önem kazanmaktadır. Çünkü üretilen ürünler uygun koşullar altında muhafaza edilmediği ve tümü tüketiciye sağlıklı bir şekilde ulaştırılamadığı durumda üretimi artırma çabaları büyük bir anlam ve önem taşımamaktadır. Bundan dolayı üretim kadar, üretilen ürünün ne ölçüde muhafaza edildiği ve hijyenik bir gıda olarak tüketiciye ulaştırılması da gıda güvenliği açısından önemlidir.

Yapılan modal analiz sonuçlarına göre, farklı cidar kalınlıklarında iki tip model silonun farklı mod değerlerinde birbirinden farklı değişim gösterdikleri ve 10 farklı moddaki frekans değerleri belirlenmiştir. Farklı cidar kalınlıklarında modal analiz sonuçlarına göre doğal frekans değerleri cidar kalınlığının artışı ile artmıştır. Modellerde cidar kalınlığının artması ile silo cidarında oluşabilecek yer değiştirme ve von Mises gerilmeleri gibi tasarım parametrelerinin cidar üzerinde daha az bir etkiye sahip olduğu belirlenmiştir. Araştırma kapsamında elde edilen modal analiz sonuçlarına ilişkin mod değerleri Dooms ve ark. (2006a; 2006b), Holler ve Meskouris (2006), Azadi ve Soltani (2010) tarafından elde edilmiş sonuçlarla benzerlik göstermektedir. Singh ve ark. (2008) farklı yükseklik/çap oranlarında siloda modal analiz sonucunda doğal frekans değişimini incelemişler ve sonuç olarak yükseklik/çap oranın artması ile silonun doğal frekanslarının arttığını belirlemişlerdir. Bu çalışmaya benzer sonuçlar Moeini ve Ahmadian (2009) tarafından da bulunmuştur. Bu çalışmada da yükseklik/çap oranının (Silo 2 için 2.25, Silo 1 için 2.3) artmasıyla doğal frekanslarda artış olduğu belirlenmiştir.

ANSYS ile yapılan analizlerde özellikle Silo 1 için doldurma ve boşaltma koşullarında gerek cidar kalınlığının ince olması, gerekse yatay ve düşey basıncın uyguladığı aşırı basınç zorlanması nedeniyle $3 \mathrm{~mm}$ cidar kalınlığından sonuç alınamamıştır.

Buğday silolarına ilişkin doldurma koşullarında Eurocode 1 ile hesaplanmış basınç yükülerinin silo cidarı üzerinde (gerek silindir bölge gerekse de huni bölgesi) neden olduğu von Mises gerilmeleri açsısından değerlendirildiğinde; yatay basınç yönünden Silo 1 için 4, 5, 6 mm'nin ve Silo 2 için 3, 4, 5, 6 mm'nin, düşey basınç yönünden Silo 1 için 4, 5, 6, 7 mm'nin ve Silo 2 için 3, 4, 5, 6 mm'lik cidar kalınlıklarının konstrüksiyon malzemesi olan çeliğin hesap akma dayanım değerinden (188000 kPa) büyük olması nedeniyle emniyetli olmadığı ancak diğer tüm cidar kalınlıkları ve sürtünme çekmesinin ise tüm kalınlıklar yönünden emniyetli oldukları saptanmıştır. 
Boşaltma koşullarında ise; yatay basınç yönünden Silo 1 için 4, 5, 6 mm'nin konstrüksiyon malzemesi olan çeliğin hesap akma dayanım değerinden (188000 kPa) büyük olması nedeniyle emniyetli olmadıkları ancak diğer cidar kalınlıkları ve sürtünme çekmesi yönünden tüm kalınlıkların emniyetli oldukları belirlenmiştir.

Araştırma sonucunda elde edilen bulgular Kovtun ve Platonov (1959), Negi ve Jofriet (1986), Teng ve Rotter (1991), Blight (1992), Goodey ve Brown (2004), Juan ve ark. (2006), Vidal ve ark. (2006) ve Vidal ve ark. (2008)'nın sonuçları ile benzerlik göstermektedir. Kovtun ve Platonov (1959) yaptıkları çalışmalarında yatay basıncın ve gerilmelerin silindir kısımdan huniye geçişte maksimum olduğunu bildirmişlerdir. Siloda doldurma işlemi devam ettikçe depolanmış ürünün dayanımı ile silo içerisinde konsolidasyon oluşabileceğini ve bu konsolidasyonda hava basıncı ile aşırı basınç etkisi yaratcağından silo cidar malzemesinin bu basınçları karşılayacak şekilde seçilmesi gerektiğini, aksi takdirde siloda patlama, çökme ve deformasyonların oluşacağını belirtmişlerdir. Askegaard ve ark. (1971), Nielsen, (1984), Blight, (1992), Vidal ve ark. (2005) ve Nielsen, (2008) merkezi boşaltmanın yapıldığı silolarda yatay basıncı deneysel olarak ölçmüşlerdir. Sonuç olarak silonun bazı lokasyonlarında deformasyonlar gözlemişler ve bu deformasyonların çoğunlukla geçiş bölgesinin alt ve üst kısımlarında olduğunu belirtmişlerdir. Bu araştırmada da geçiş bölgelerinde deformasyonlar belirlenmiş olup sonuçlar diğer araştırmacıların elde etmiş olduğu sonuçlar ile benzerlik göstermektedir.

Nielsen (1983), Negi ve Jofriet (1986) ile Nielsen ve Weidne (1998) silolar üzerinde yapmış oldukları çalışmalarında yatay basıncın silonun tepe noktasından geçiş bölgesine doğru arttığını, geçişin alt bölgesinden çıkış ağzına doğru ise azaldığını bildirmişlerdir. Teng ve Rotter (1991), çelik bir siloda doldurma esnasında yatay basıncın silodaki von Mises gerilmelerinin geçiş bölgesinde maksimum olduğunu ve deformasyonlara yol açtığını tespit etmişlerdir. Bu bağlamda oluşan bu deformasyonları ortadan kaldırabilmek için geçiş bölgesindeki cidar kalınlığının artııımasını önermişlerdir. Mevcut araştırmada da model siloların tepe noktasında basınç yüklerinin, sıfır çıkış ağzına doğru artış gösterdiği belirlenmiş̧tir.

Blight (1992) merkezi doldurmanın yapıldığı çelik bir siloda yatay basıncın değişimini deneysel olarak incelemiştir. Sonuç olarak silo yüksekliğinin artması ile silo yüzeylerindeki yatay basıncın arttığını saptamıştır. Goodey ve Brown (2004) 10 m yüksekliğinde ve 1.5 m çapında oluşturmuş olduğu model bir siloda yatay basıncın cidarlar üzerinde oluşturduğu gerilmeleri farklı huni eğim açıları $\left(15^{\circ}, 30^{\circ}, 45^{\circ}, 60^{\circ}, 70^{\circ}\right)$ açısından incelemişlerdir. Çalışma sonucunda huni eğim açısının artmasıyla hunide oluşan gerilmelerin arttığını ve aynı zamanda gerilme artışının huninin bazı lokasyonlarında deformasyonlara neden olduğunu belirlemişlerdir.

Juan ve ark. (2006), farklı cidar kalınlıklarında (1, 1.5, 2 mm) doldurma koşullarında huni cidarları üzerinde yatay basıncın oluşturduğu gerilmeleri araştırmışlardır. Çalışmada en düşük gerilme değerinin 2 mm cidar kalınlığında, en yüksek gerilme değerinin ise $1 \mathrm{~mm}$ cidar kalınlığında olduğunu belirlemişlerdir. Vidal ve ark. (2006), çelik aksamlı bir siloda yükseklik - gerilme değişimini araştırmışlar ve araştırma sonucunda gerilmelerin basma ve çekme gerilme şeklinde olduğunu ayrıca bazı lokasyonlarda deformasyonların oluştuğunu gözlemlemişlerdir. Ayrıca silonun geçiş bölgesi etrafında gerilmelerin maksimum oluştuğunu, çıkışta ise minimum olduğunu belirtmişlerdir. Rotter (2008) çalışmasında, doldurma esnasında silo tam doldurulana kadar basınçların kademeli olarak artış gösterdiğini saptamıştır. Yani doldurma işlemi başladığında silonun çıkış ağzında basınç değerinin düşük olduğunu, sonra geçiş bölgesine doğru arttığını, daha sonra tepe noktasına doğru tekrar azaldığını ifade etmiştir. Kovtun ve Platonov (1959) silo yüksekliğinin artması ile düşey basıncın arttığını ve geçişte maksimum olduğunu ve aynı durumu silo yüzeyinde oluşan gerilmelerde de gözlemlemişlerdir. Mark ve ark. (1999), doldurma esnasında sürtünme çekmesinin silo yüksekliğinin artışı ile arttığını ve sürtünme çekmesi basınç yükünün oluşturduğu gerilmelerin silo yüksekliğinin $1,1.5$ ve 2 m'de değişmediğini 0.5 m yükseklikte değişim gösterdiğini saptamışlardır. Wojcik ve ark. (2003) boşaltma koşullarında yatay basıncın siloda oluşturduğu gerilmelerin etkisini sonlu elemanlara göre değerlendirmişler ve sonuçta hunide maksimum gerilmenin geçişte olduğunu, huni çeperlerine doğru deformasyonların olduğunu ifade etmişlerdir. Juan ve ark. (2006), farklı cidar kalınlıklarında (1, $1.5,2 \mathrm{~mm}$ ) huni cidarları üzerinde sürtünme çekmesinin cidarlar üzerinde oluşturduğu gerilmeleri incelemişler ve en düşük gerilme değerinin 2 mm cidar kalınlığında olduğunu tespit etmişlerdir. Brown (2008), siloda boşaltma esnasında huni tasarımının diğer silo elemanlarının tasarımına göre kompleks olduğunu ve EN 1991-4 huni tasarımında iki ana basıncın (cidar normal basınçları ve sürtünme çekmesi) düşünülerek tasarım yapılması gerektiğini belirtmiştir. Ayrıca huni bölgesine geçişte oluşan yatay basınçlar, gerilme ve sürtünme çekmesi üzerine depolanmış ürünün birim ağırlığının ve huni geometrisinin son derece önemli olduğunu tespit etmiştir.

\section{SONUÇ}

Çalışma kapsamında buğday tahılı silosuna ilişkin 64 farklı simülasyon yapılmıştır. Yapılan 64 simülasyon sonucunda buğday tahılının muhafazası için tasarlanan 8 farklı cidar kalınlığında Silo 1 ve Silo 2'de en fazla von Mises gerilmesi değeri doldurma koşullarında düşey basınç durumunda elde edilirken, boşaltma koşullarında ise 
yatay basınç durumunda elde edilmiştir. İki farklı siloda von Mises gerilmelerinin maksimum değerleri huni başlangıç bölgesinde veya buraya yakın yerlerde meydana gelmiştir. Bu duruma huni bölgesinde oluşan basıncın maksimum olması ve depolanacak ürünlerin bu bölgeyi daha fazla zorlaması neden olmaktadır. Silolanacak buğday tahılının yaratacağı basınç etkisi ve depolama kapasitesi göz önüne alındığında siloda kalıcı deformasyona yol açmayacak optimum cidar kalınlıkları yönünden uygun silo tipinin Silo 1 ve $8 \mathrm{~mm}$ cidar kalınlığının olduğu belirlenmiştir.

Silolar, mühendislik alanları arasındaki tasarımı zor olan yapılardan birisidir. Bu araştırma sonucunda elde edilen bulgulara göre buğday silolamada kullanılabilecek silo konstrüksiyonunun üniform olmayan basınç yükleri nedeniyle kolayca deforme olabildiği gözlemlenmiştir. Buğday muhafazasında kullanılacak silindirik gövdeli konik çıkış ağızıı siloların tasarımı yapılmadan önce mutlaka doldurma ve boşaltma koşullarındaki yatay, düşey ve huni basınçları hesaplanmalıdır. Buna bağlı olarak silo inşası öncesinde ANSYS veya herhangi bir yazılım yardımı ile gerekli simülasyonların yapılması konstrüksiyona yönelik aksaklıkların önceden giderilmesi açısından önemlidir.

\section{ÇIKAR ÇATIŞMASI}

Herhangi bir çıkar çatışması yoktur.

\section{YAZAR KATKISI}

Hakan Kibar; çalışmanın tasarlanması, simülasyonların yapılması, elde edilen verilerin değerlendirilmesi ve makale yazma işlemlerinin tümünü gerçekleştirmiştir.

\section{TEŞEKKÜR}

Bu araştırmaya 2012-FBE-B20 proje numarası ile destek sağlayan Iğdır Üniversitesi Bilimsel Araştırma Projeleri Koordinatörlüğüne teşekkür ederim.

\section{KAYNAKLAR}

ACl. (1997). Standard 313-97: Standard Practice for Design and Construction of Concrete Silos and Stacking Tubes for Storing Granular Materials. Farmington Hills, Michigan, US.

ANSYS Inc. (2013). ANSYS Theory Manual Release 14.0. Swanson Analysis System, USA.

Askegaard, V., Bergholdt, M., \& Nielsen, J. (1971). Problems in connection with pressure cell measurements in silos. Bygningsstatiske Meddelelser, 2.

Ayuga, F., Aguado, P., Gallego, E., \& Ramírez, A. (2006). Experimental tests to validate numerical models in silos design. In 2006 ASAE Annual Meeting (p. 1), American Society of Agricultural and Biological Engineers.

Azadi, M. R. E., \& Soltani, A. A. (2010). The effects of soil-foundation-structure interaction on the dynamic response of Delijan cement-storage silo under earthquake loading. Electronic Journal of Geotechnical Engineering, 15, 659-76.

BIS. (1974). Criteria for Design of Reinforced Concrete Bins for the Storage of Granular and Powdery Materials. Bureau of Indian Standard.

Blight, G. E. (1992). Design implications of measured pressures and strains in silos. Journal of Structural Engineering, 118(10), 2729-2742.

Brown, C. J. (2008). Developments in the design of rectangular plan form silos. proceedings of the international conference on structures and granular solids: from scientific principles to engineering applications, The Royal Society of Edinburgh, Scotland, UK.

CEN. (2007). Eurocode 1: Actions on Structures, Part 4: Silos and Tanks. European Committee for Normalisation, Brussels.

Dooms, D., Degrande, G., De Roeck, G., \& Reynders, E. (2006a). Finite element modelling of a silo based on experimental modal analysis. Engineering Structures, 28(4), 532-542.

Dooms, D., De Roeck, G., \& Degrande, G. (2006b). Influence of the group positioning of cylinders on the wind pressure distribution in the post-critical regime. In ECCOMAS CFD 2006: Proceedings of the European Conference on Computational Fluid Dynamics, Egmond aan Zee, The Netherlands.

Eurocode 1. (2003). Basis of Design and Actions on Structures (EN 1991-4), Part 4: Actions in Silo and Tanks. European Committee for Standardisation, Brussels. 
Eurocode 3. (2004). Design of Steel Structures (EN 1993-1-3), Part 1-3: General Rules- Supplementary Rules for Cold Formed Thin Gauge Members and Sheeting. European Committee for Standardisation, Brussels.

Gallego, E., Rombach, G. A., Neumann, F., \& Ayuga, F. (2010). Simulations of granular flow in silos with different finite element programs: ANSYS vs. Silo. Transactions of the ASABE, 53(3), 819-829.

Goodey, R. J., \& Brown, C. J. (2004). The influence of the base boundary condition in modelling filling of a metal silo. Computers \& Structures, 82(7-8), 567-579.

Guaita, M., Couto, A., \& Ayuga, F. (2003). Numerical simulation of wall pressure during discharge of granular material from cylindrical silos with eccentric hoppers. Biosystems Engineering, 85(1), 101-109.

Guines, D., Ragneau, E., \& Kerour, B. (2001). 3D finite-element simulation of a square silo with flexible walls. Journal of engineering Mechanics, 127(10), 1051-1057.

Holler, S., \& Meskouris, K. (2006). Granular material silos under dynamic excitation: numerical simulation and experimental validation. Journal of Structural Engineering, 132(10), 1573-1579.

Horabik, J., \& Molenda, M. (2017). Distribution of static pressure of seeds in a shallow model silo. International Agrophysics, 31(2), 167.

Janssen HA (1895). Investigations of pressure of grain in silo (in German). Vereins Eutscher Ingenieure Zeitschrift, 39, 10451049.

Jayachandran, L. E., Nitin, B., \& Rao, P. S. (2019). Simulation of the stress regime during grain filling in bamboo reinforced concrete silo. Journal of Stored Products Research, 83, 123-129.

Juan, A., Moran, J. M., Guerra, M. I., Couto, A., Ayuga, F., \& Aguado, P. J. (2006). Establishing stress state of cylindrical metal silos using finite element method: Comparison with ENV 1993. Thin-Walled Structures, 44(11), 1192-1200.

Kibar H. (2011). Tombul fındık depolamasında tane özelliklerine bağlı olarak ANSYS programıyla optimum silo tasarımı. Doktora Tezi, Ondokuz Mayıs Üniversitesi, Fen Bilimleri Enstitüsü, Samsun.

Kibar, H. (2016). Determining the functional characteristics of wheat and corn grains depending on storage time and temperature. Journal of Food Processing and Preservation, 40(4), 749-759.

Kibar, B., \& Kibar, H. (2017). Determination of the nutritional and seed properties of some wild edible plants consumed as vegetable in the Middle Black Sea Region of Turkey. South African Journal of Botany, 108, 117-125.

Kibar, H., \& Kibar, B. (2019). Changes in some nutritional, bioactive and morpho-physiological properties of common bean depending on cold storage and seed moisture contents. Journal of Stored Products Research, 84, 101531.

Kovtun, A. P., \& Platonov, P. N. (1959). Davlenie zerna na stenki silosov elevatorov [Grain loads on the silo walls]. Mukomolno Elevatornaia Promyshlennost, 25(12), 22-24 (Thompson ve ark. 1995'den alıntı).

Lapko, A. (2010). Pressure of agricultural bulk solids under eccentric discharging of cylindrical concrete silo bin. International Agrophysics, 24(1), 51-56.

Manbeck, H. B., Puri, V. M., \& Britton, M. G. (1995). Structural loads in grain storages. DS Jayas, ND G White, and WE Muir, 465526.

Mark, J., Holst, F. G., Ooi, J. Y., Rotter, J. M., \& Rong, G. H. (1999). Numerical modeling of silo filling 1: Continuum analysis. Journal of Engineering Mechanics, 125, 94-103.

Moeini, S. A., \& Ahmadian, M. T. (2009). Structural analysis of stiffened fgm thick walled cylinders by application of a new cylindrical super element. World Academy of Science, Engineering and Technology, 58, 116-121.

Nielsen, J. (1984). Pressure measurements in a full-scale fly ash silo. Particulate Science and Technology, 2(3), $237-246$.

Negi, S. C., \& Jofriet, J. C. (1986). Computer-aided prediction of silo-wall pressures. Applied Engineering in Agriculture, 2(2), 148-152.

Nielsen, J. (1983). Load distribution in silos influenced by anisotropic grain behaviour. International Conference on Bulk Materials Storage, Handling and Transportation. Newcastle, Australia.

Nielsen, J. (1998). The choice of constitutive laws for silo media. In C. J. Brown, \& J. Nielsen (Eds.). Silos. Fundamentals of Theory, Behaviour and Design (pp. 539-550). Spon press. Newyork, USA: CRC Press.

Nielsen, J. (2008). From silo phenomena to load models. Proceedings of The International Conference on Structures and Granular Solids: From Scientific Principles to Engineering Applications, The Royal Society of Edinburgh, Scotland, UK.

Reimbert, M. L., \& Reimbert, A. M. 1987. Silos. Theory and practice. Vertical Silos, Horizontal Silos (Retaining Walls). Lavoisier Publishing. 
Singh, J., Sharma, V. R., \& Khullar, N. K. (2008). Analysis of hopper bottom cylindrical silos subjected to earthquakes. In The $12^{\text {th }}$ International Conference of International Association for Computer Methods and Advances in Geomechanics, Goa, India.

Teng, J. G., \& Rotter, J. M. (1991). Strength of welded steel silo hoppers under filling and flow pressures. Journal of Structural Engineering, 117, 2567-2583.

Thompson, S. A., Galili, N., \& Williams, R. A. (1995). Lateral pressures during filling of a full-scale grain bin. Transactions of the ASAE, 38(3), 919-926.

Vidal, P., Guaita, M., \& Ayuga, F. (2004). Simulation of discharging processes in metallic silos. In 2004 ASAE Annual Meeting (p. 1), American Society of Agricultural and Biological Engineers.

Vidal, P., Guaita, M., \& Ayuga, F. (2005). Discharge from cylindrical slender steel silos: finite element simulation and comparison with Eurocode 1. Transactions of the ASAE, 48(6), 2315-2321.

Vidal, P., Gallego, E., Guaita, M., \& Ayuga, F. (2006). Simulation of the filling pressures of cylindrical steel silos with concentric and eccentric hoppers using 3-dimensional finite element models. Transactions of the ASABE, 49(6), 1881-1895.

Vidal, P., Gallego, E., Guaita, M., \& Ayuga, F. (2008). Finite element analysis under different boundary conditions of the filling of cylindrical steel silos having an eccentric hopper. Journal of Constructional Steel Research, 64(4), 480-492.

Walker, D., \& Blanchard, M. (1967). Pressures in experimental coal hoppers. Chemical Engineering Science, 22(12), $1713-1745$.

Wójcik, M., Enstad, G. G., \& Jecmenica, M. (2003). Numerical calculations of wall pressures and stresses in steel cylindrical silos with concentric and eccentric hoppers. Particulate Science and Technology, 21(3), 247-258.

Wójcik, M., Sondej, M., Rejowski, K., \& Tejchman, J. (2017). Full-scale experiments on wheat flow in steel silo composed of corrugated walls and columns. Powder Technology, 311, 537-555.

Zheng, Q. J., \& Yu, A. B. (2015). Finite element investigation of the flow and stress patterns in conical hopper during discharge. Chemical Engineering Science, 129, 49-57. 


\section{EKLER}

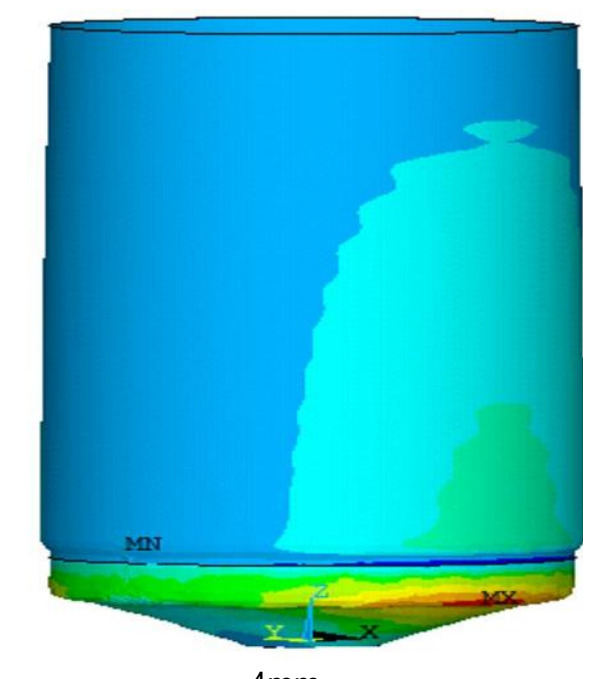

$4 \mathrm{~mm}$

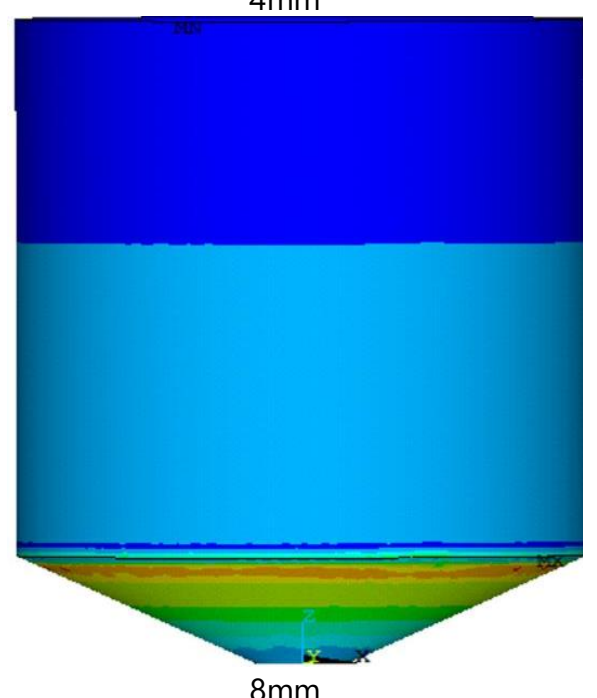

$8 \mathrm{~mm}$

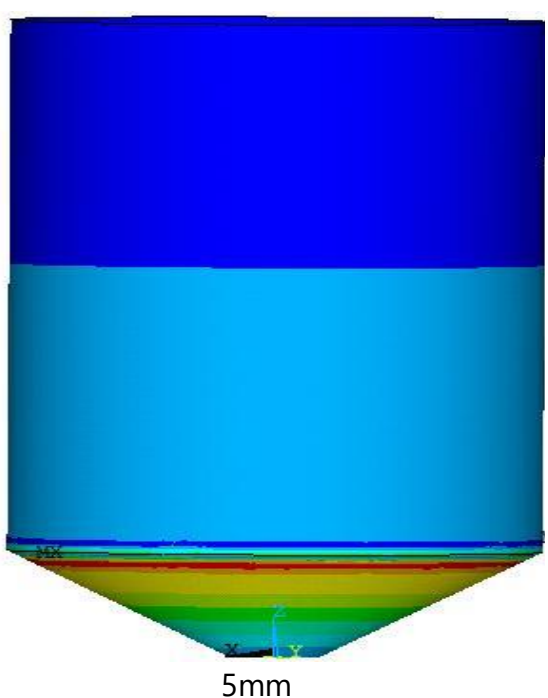

$5 \mathrm{~mm}$

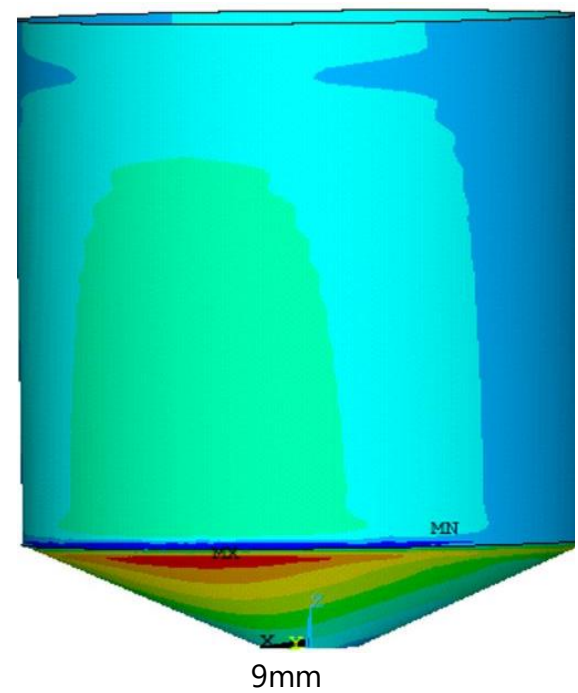

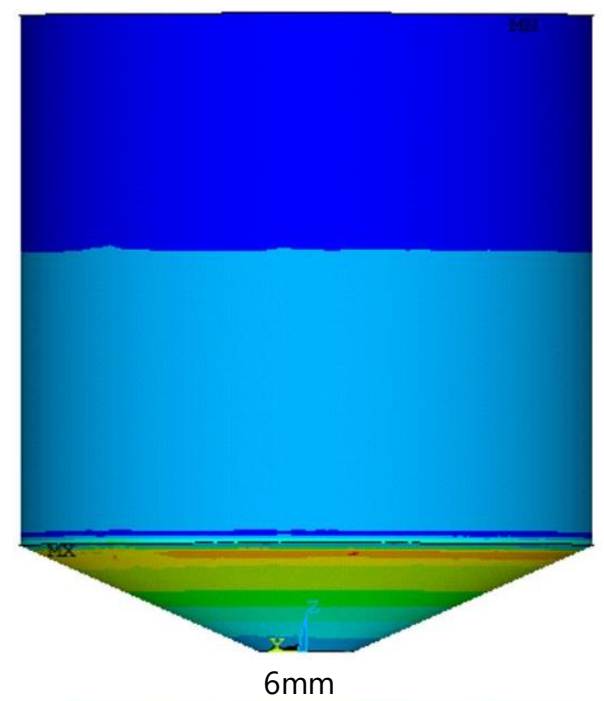

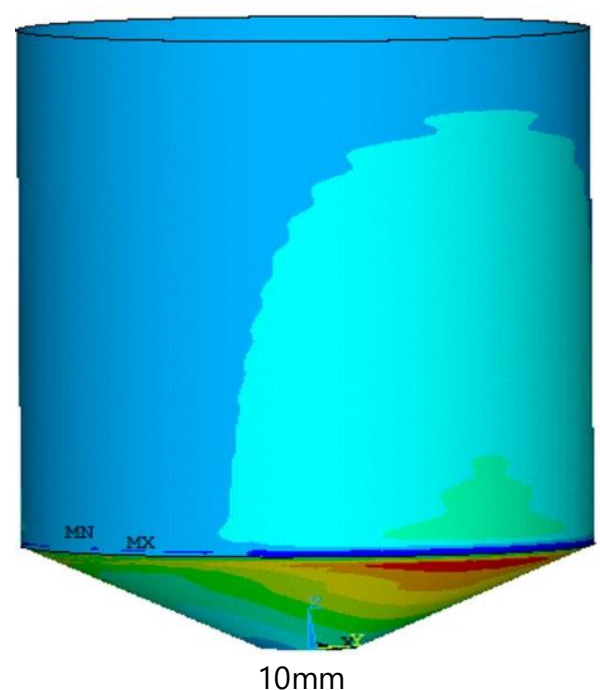

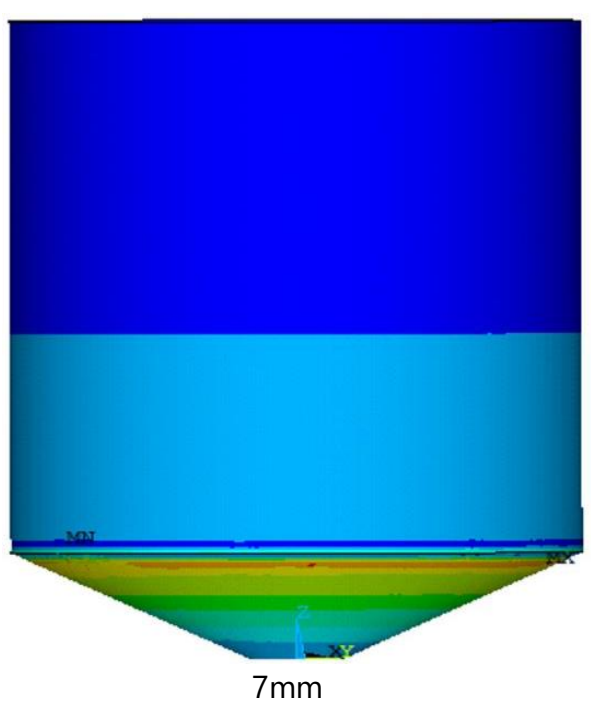

$7 \mathrm{~mm}$

Ek 1. Doldurma koşullarında yatay basınç yükünün Silo 1 cidarı üzerinde oluşturduğu gerilme dağıımı.

Supplementary 1. The stress distribution created by the horizontal pressure load on Silo 1 wall under filling conditions. 

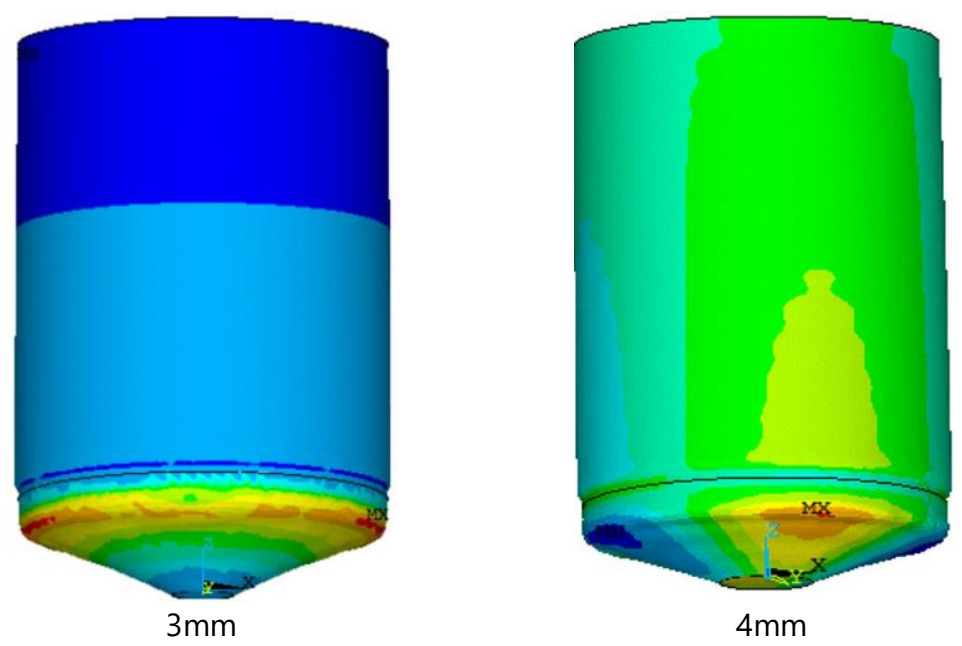

$4 \mathrm{~mm}$

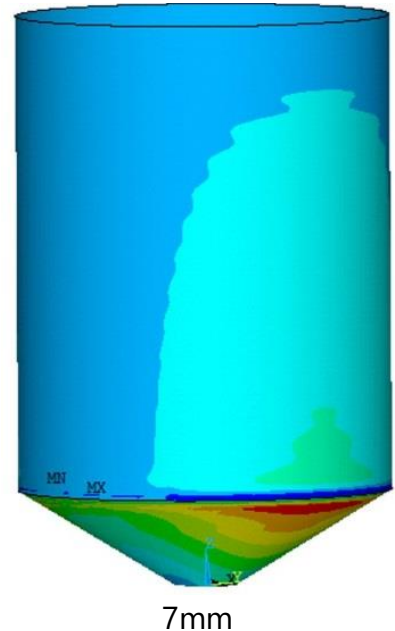

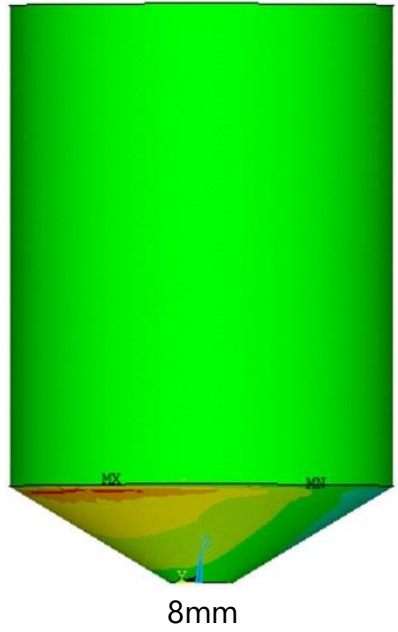
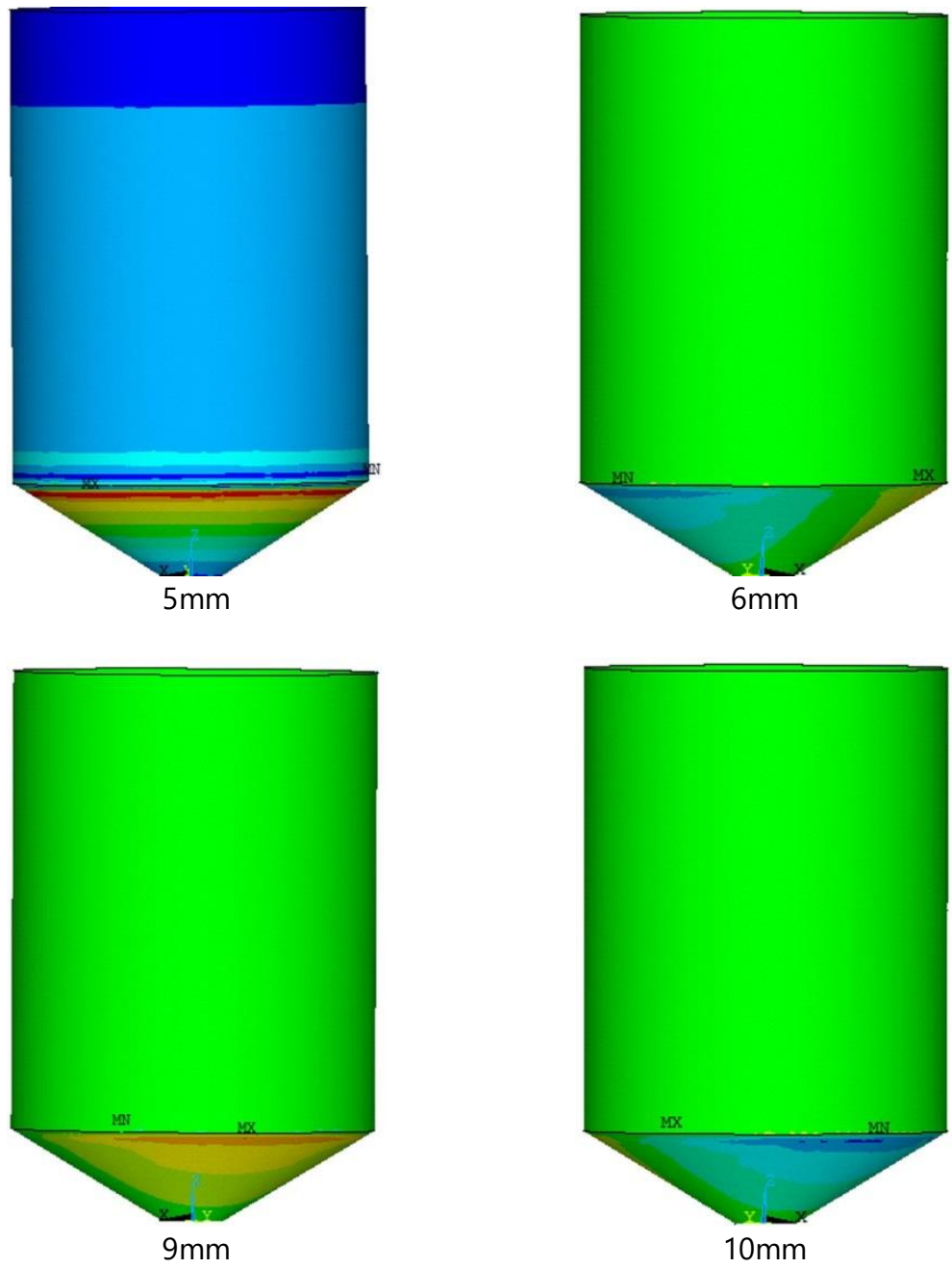

Ek 2. Doldurma koşullarında yatay basınç yükünün Silo 2 cidarı üzerinde oluşturduğu gerilme dağılımı.

Supplementary 2. The stress distribution created by the horizontal pressure load on Silo 2 wall under filling conditions. 


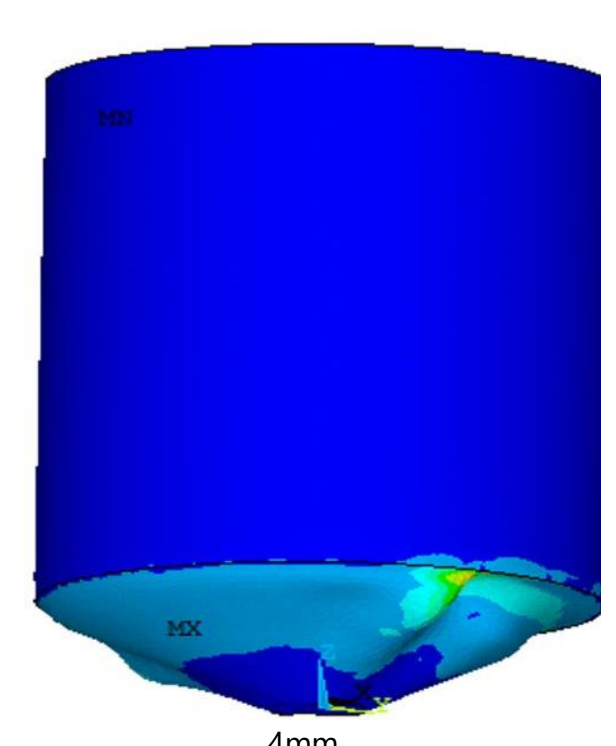

$4 \mathrm{~mm}$

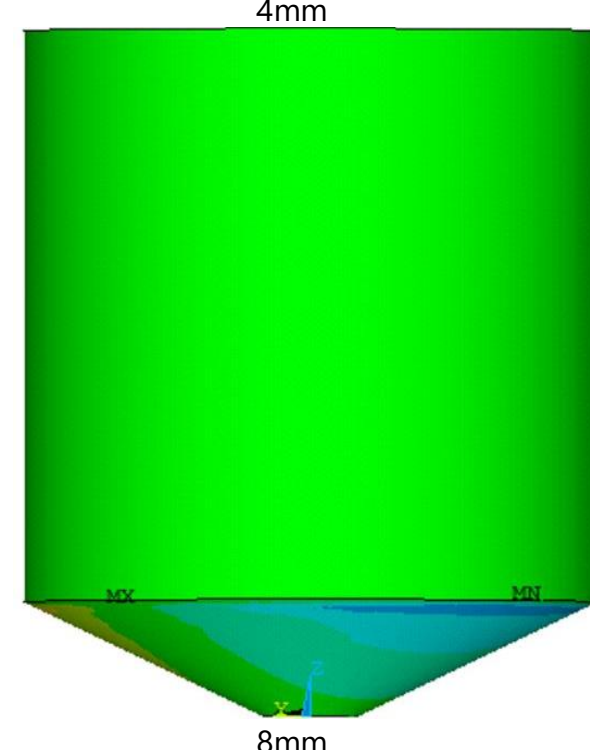

$8 \mathrm{~mm}$
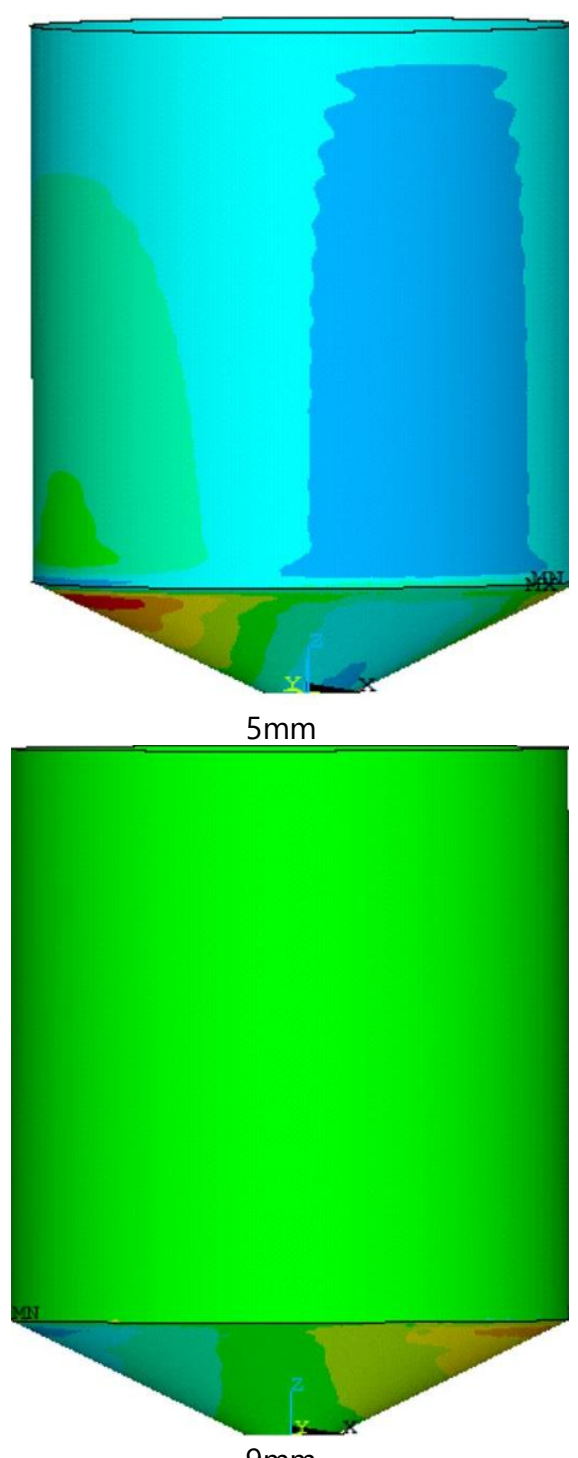

$9 \mathrm{~mm}$

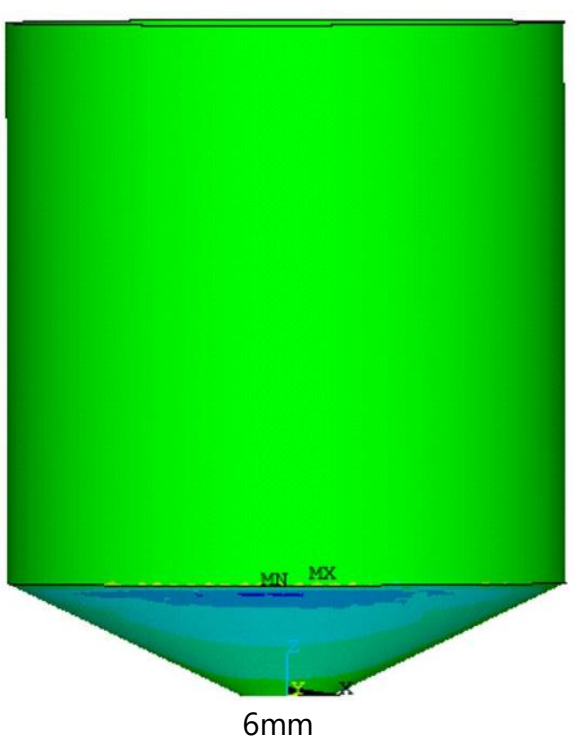

$6 \mathrm{~mm}$

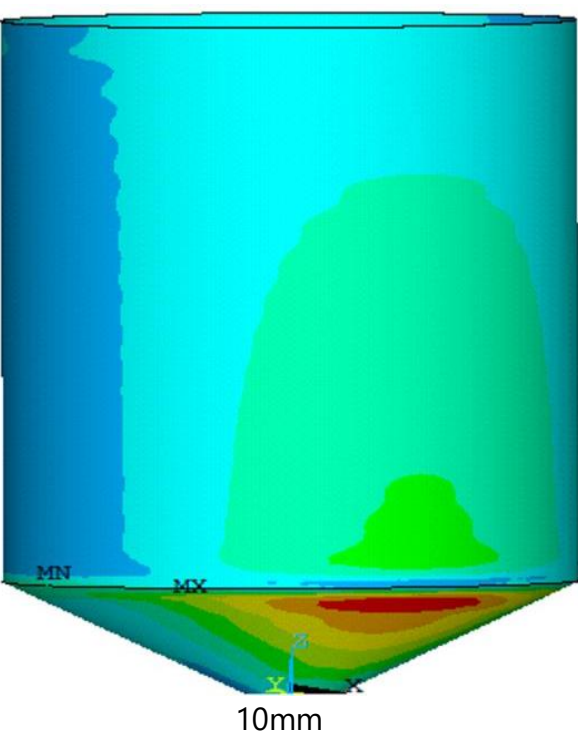

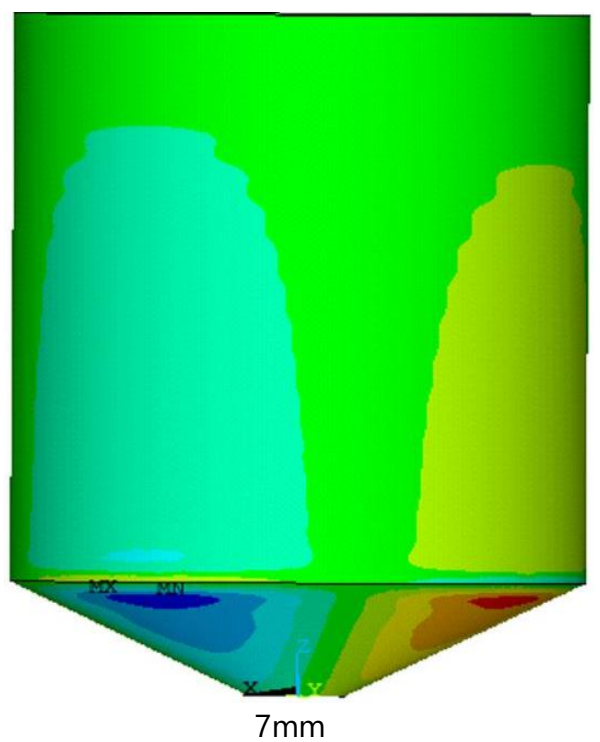

$7 \mathrm{~mm}$

Ek 3. Doldurma koşullarında düşey basınç yükünün Silo 1 cidarı üzerinde oluşturduğu gerilme dağılımı.

Supplementary 3. The stress distribution created by the vertical pressure load on Silo 1 wall under filling conditions. 

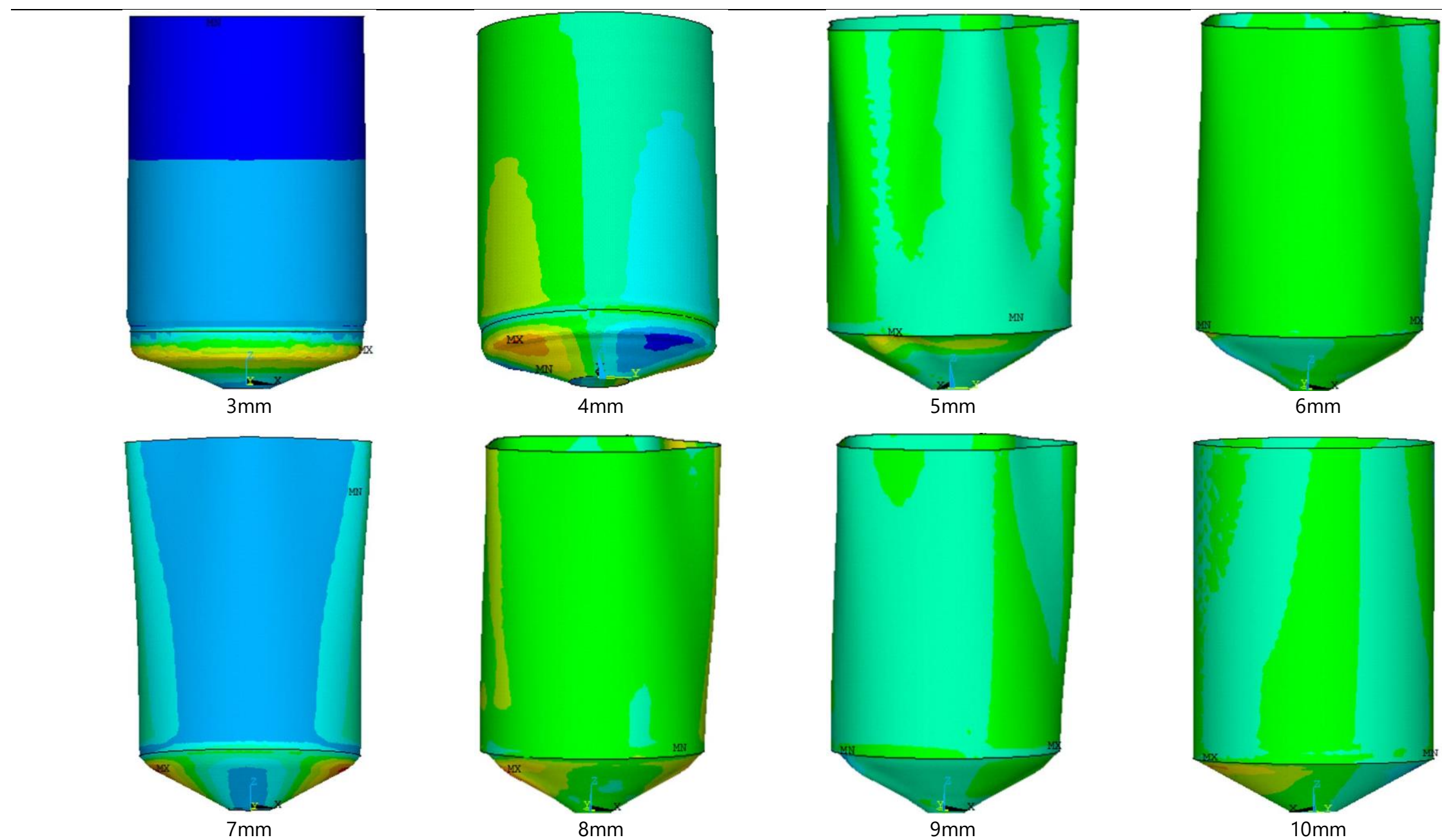

Ek 4. Doldurma koşullarında düşey basınç yükünün Silo 2 cidarı üzerinde oluşturduğu gerilme dağılımı.

Supplementary 4. The stress distribution created by the vertical pressure load on Silo 2 wall under filling conditions. 


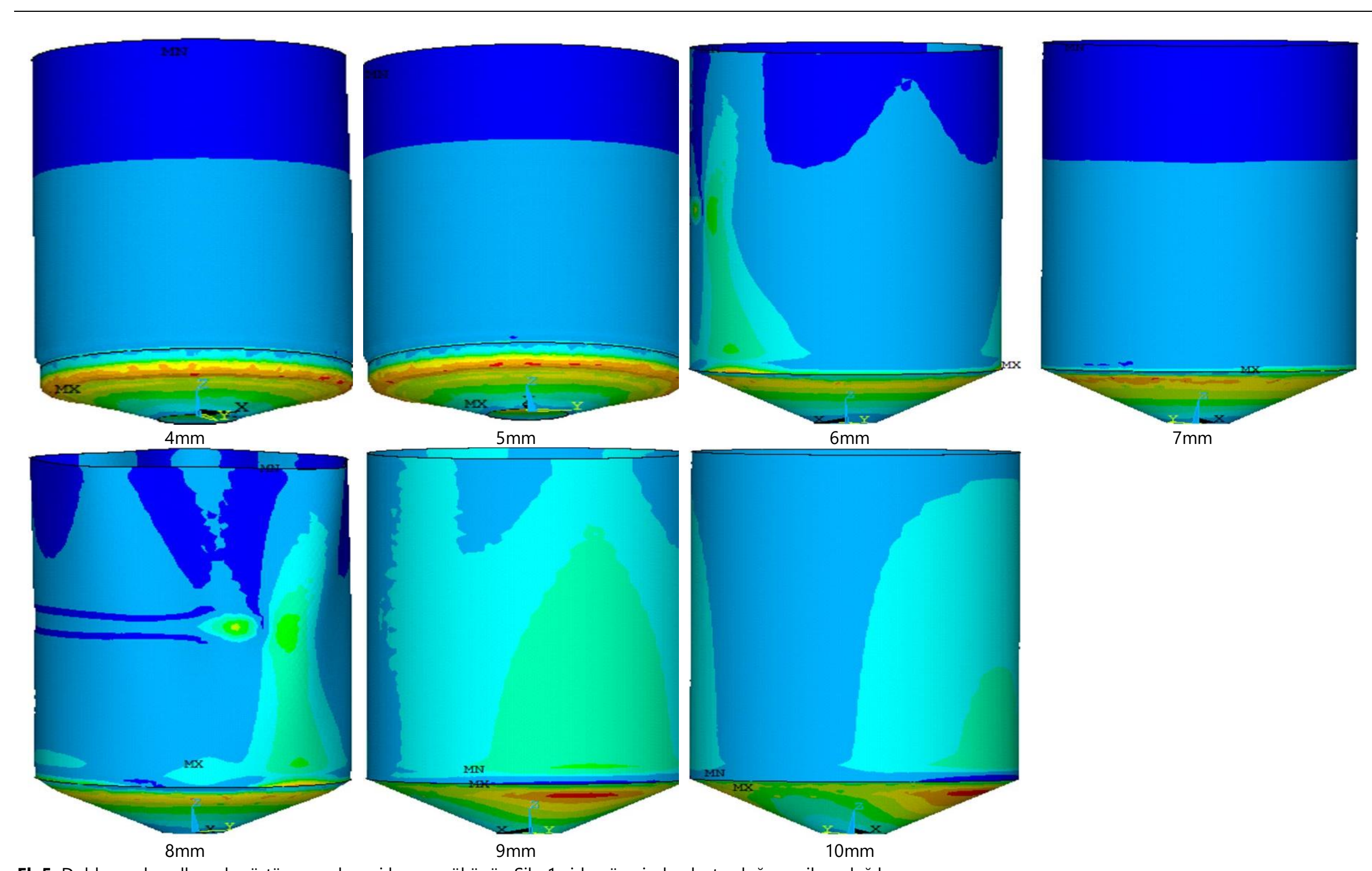

Ek 5. Doldurma koşullarında sürtünme çekmesi basınç yükünün Silo 1 cidarı üzerinde oluşturduğu gerilme dağılımı. Supplementary 5. The stress distribution created by friction traction pressure load on Silo 1 wall under filling conditions. 

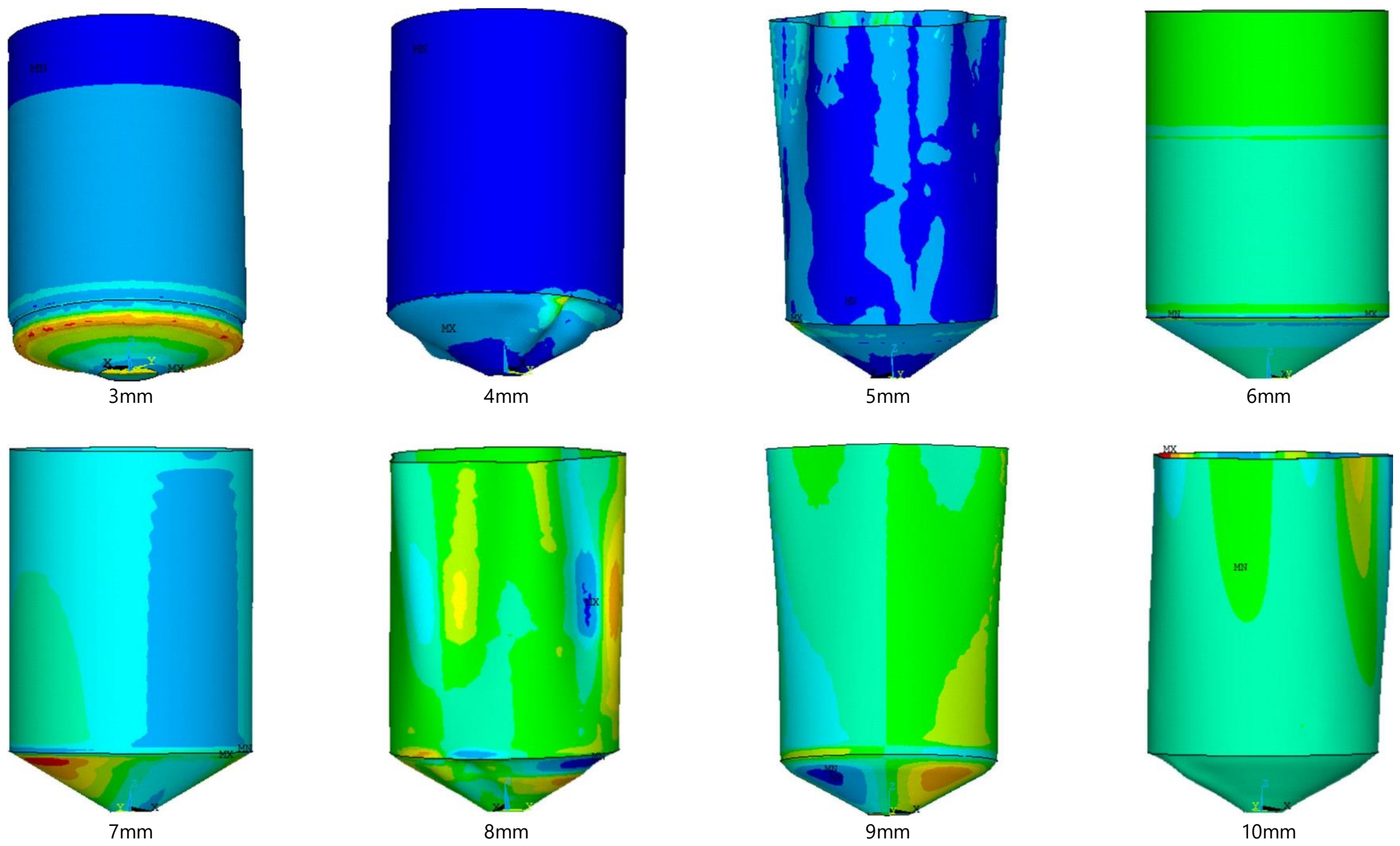

Ek 6. Doldurma koşullarında sürtünme çekmesi basınç yükünün Silo 2 cidarı üzerinde olușturduğu gerilme dağılımı. Supplementary 6 . The stress distribution created by friction traction pressure load on Silo 2 wall under filling conditions. 

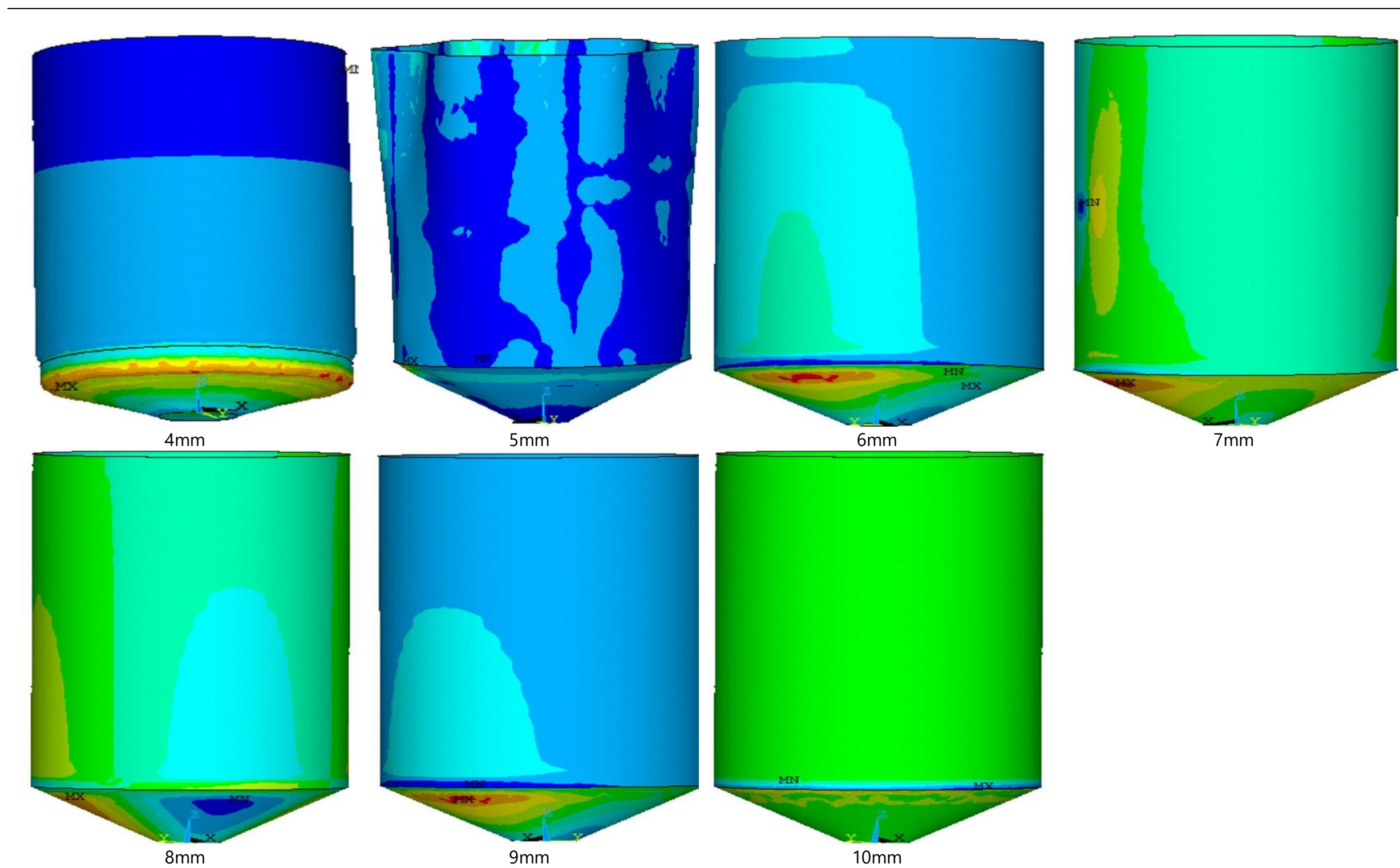

Ek 7. Boşaltma koşullarında yatay basınç yükünün Silo 1 cidarı üzerinde oluşturduğu gerilme dağılımı.

Supplementary 7. The stress distribution created by the horizontal pressure load on Silo 1 wall under discharge conditions. 


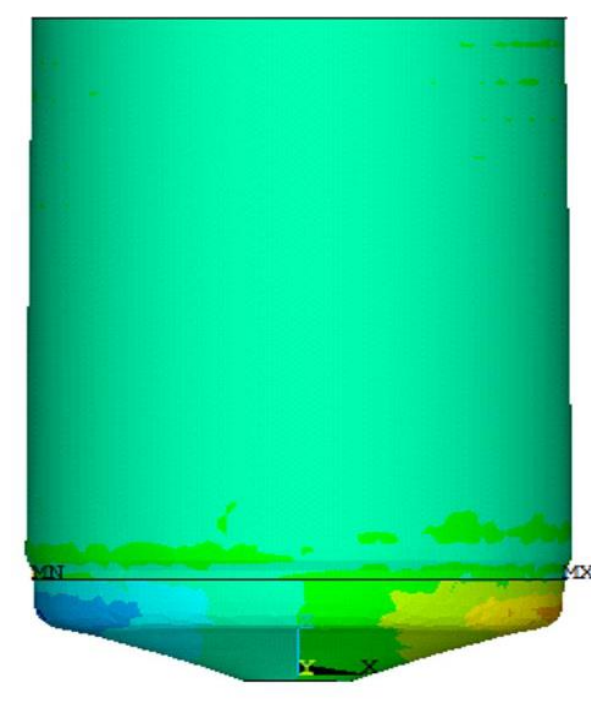

$4 \mathrm{~mm}$

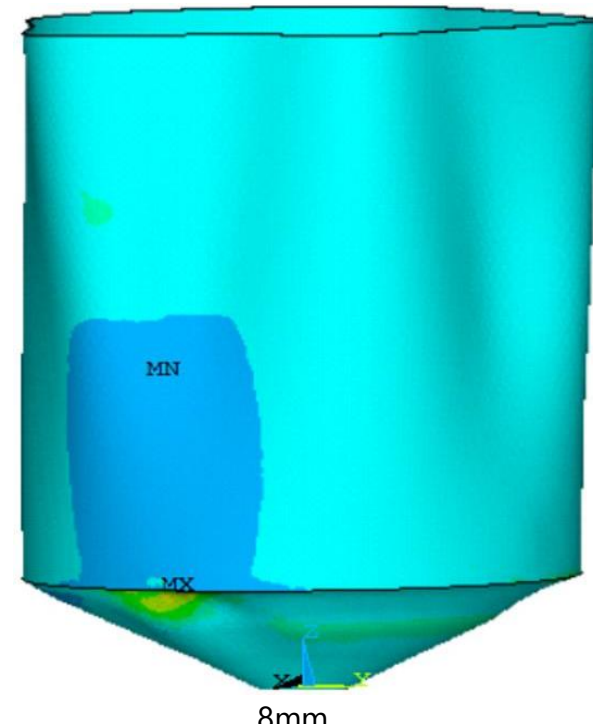

$8 \mathrm{~mm}$
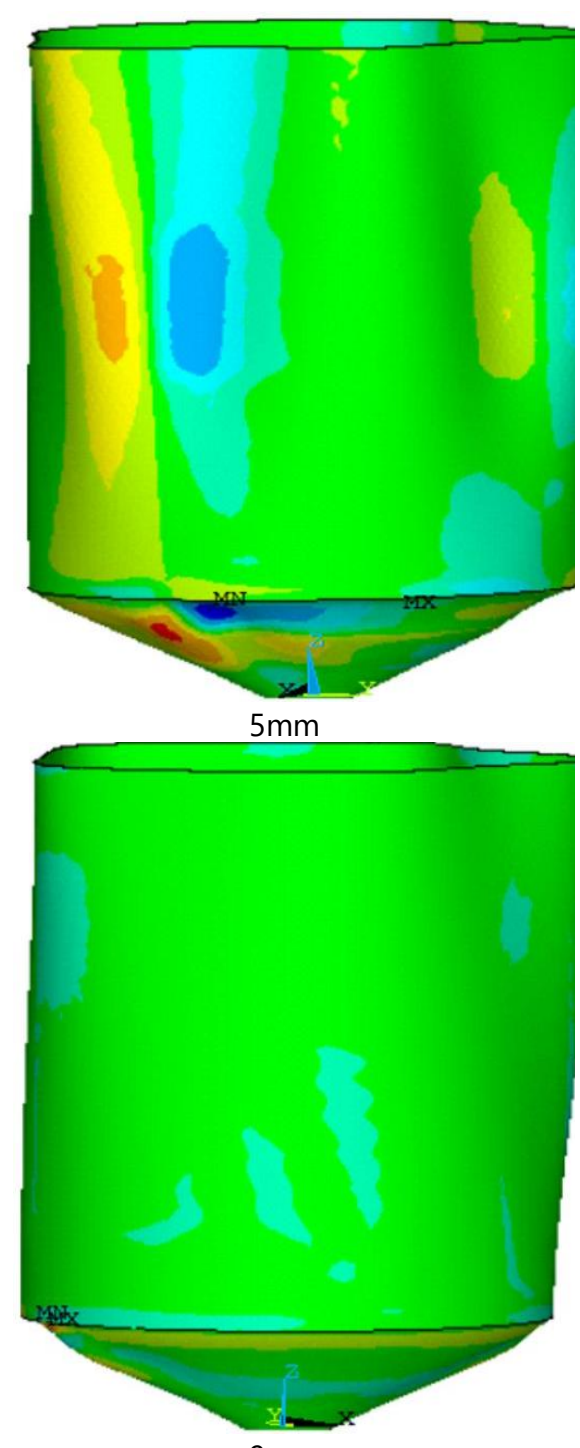
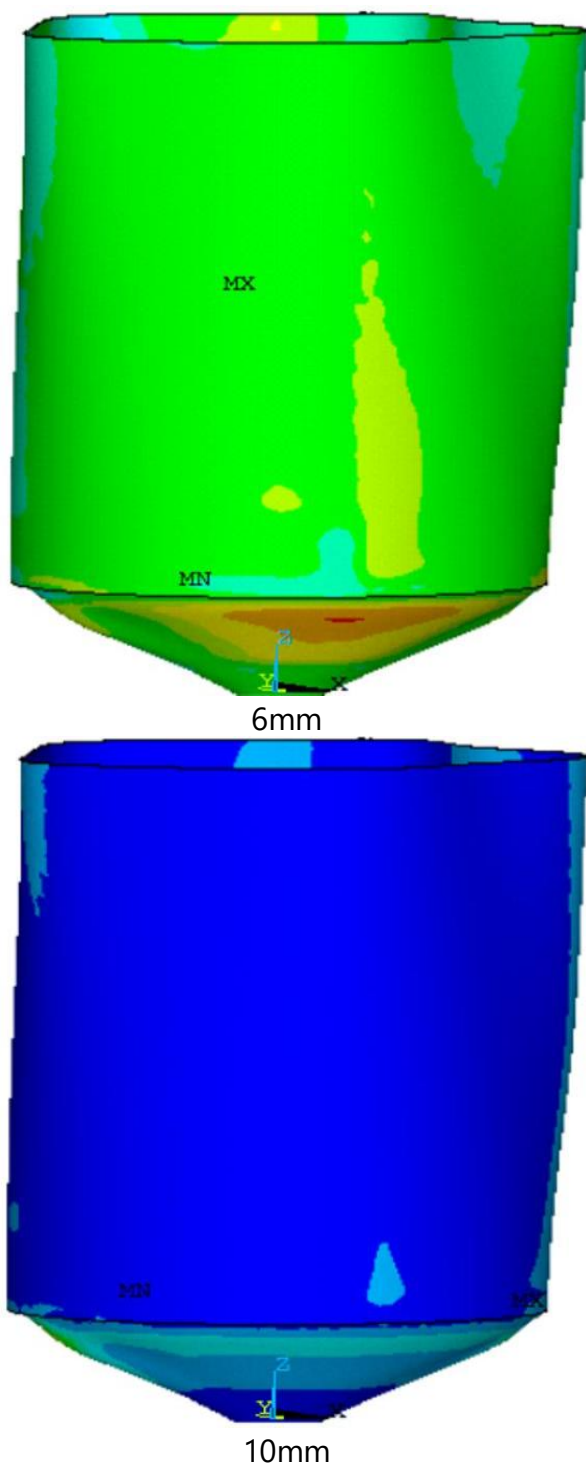

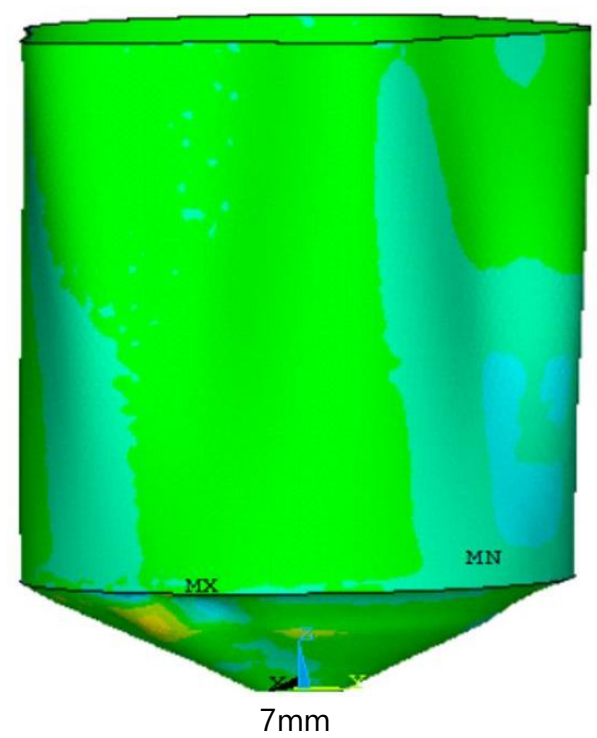

$7 \mathrm{~mm}$

Ek 8. Boşaltma koşullarında sürtünme çekmesi yükünün Silo 1 cidarı üzerinde oluşturduğu gerilme dağılımı.

Supplementary 8 . The stress distribution caused by friction traction load on Silo 1 wall under discharge conditions. 